\title{
CULTIVO DEL MAÍZ Y RITUALES DEL TIEMPO EN EL VALLE DE IXTLAHUACA-JOCOTITLÁN, ESTADO DE MÉXICO ${ }^{1}$
}

\section{CULTIVO DE MILHO E OS RITUAIS DO TEMPO NO VALE DE IXTLAHUACA-JOCOTITLÁN, MÉXICO}

\section{CORN PLANTATION AND THE RITUALS OF THE TIME IN THE IXTLAHUACA-JOCOTITLÁN VALLEY, MEXICO}

\author{
Laura Reyes Montes \\ Profesora-investigadora de Tiempo Completo \\ Facultad de Antropología, Universidad Autónoma del Estado de México (UAEM), \\ Dirección Postal: Mariano Matamoros sur s/n \\ Colonia Universidad \\ C.P. 50130 Toluca, Estado de México. Co-el \\ Teléfono 017222194615 ext. 105 \\ reyeslau13@hotmail.com
}

Beatriz Andrea Albores Zárate

Profesora-investigadora de El Colegio Mexiquense, A.C.

Dirección Postal: Ex Hacienda Santa Cruz de los Patos, A.C.,

Colonia Cerro del Murciélago,

C.P. 51350 Zinacantepec,

Estado de México. Co-el

Teléfono 017222799908

017222180100 (ext. 182)

balbores@cmq.edu.mx

\section{Resumen}

A partir de información etnográfica se exponen dos variantes agrícolas de humedad y temporal de la región del centro de México que ocupó una importante y enigmática jurisdicción político-administrativa. Se trata del Matlatzinco, que albergó de manera mayoritaria a hablantes de los cuatro idiomas otomianos -matlatzinca, otomí, mazahua y ocuilteco- hasta el siglo XV cuando ocurrió la invasión mexica, cuya lengua era el náhuatl. El territorio aproximado del Matlatzinco empezó a conocerse como valle de Toluca al comienzo del virreinato en el siglo XVI. La primera variante agrícola

\footnotetext{
${ }^{1}$ Este trabajo se basa en uno de los avances del proyecto: Relaciones entre agricultura, ambiente y cultura en una región agrícola del Valle de Ixtlahauca, México: Un enfoque antropológico. El proyecto fue desarrollado por Laura Reyes Montes, durante la estancia de Investigación Posdoctoral en El Colegio Mexiquense, A.C., de marzo-2007 a febrero-2008, con la asesoría académica de Beatriz Albores Zárate. Un borrador de lo que se presenta se entregó para su discusión - con el título "Agricultura y rituales del tiempo en el Valle de Ixtlahuaca-Jocotitlán, Estado de México- a la Serie Documentos de Investigación, que publica El Colegio Mexiquense, A.C.
} 
proviene del valle de Ixtlahuaca-Jocotitlán - que se ubica en la zona serrana de aquella región-, a la cual nos referiremos desde un enfoque comparativo con la variante de la zona lacustre del antiguo Matlatzinco. La finalidad es dar a conocer dos de las maneras en las que la agricultura maicera de temporal es adaptada a entornos que sobrepasan los 2,000 metros sobre el nivel del mar. En estos ambientes tan elevados -donde sólo es posible una cosecha anual a causa del despliegue de las heladas sobre todo- el cultivo debe emprenderse antes de que empiece la época lluviosa. Así, los casos de las dos zonas mencionadas ejemplifican el detallado conocimiento milenario que la población tiene de su medio natural y el ingenio con el que enfrenta las limitantes ambientales, a fin de obtener la humedad necesaria para la consecución del grano divino del maíz. También se mencionan las principales festividades agrícolas, destacándose una de éstas por sus implicaciones relativas a la forma mesoamericana de conceptuar el mundo (conceptuación del mundo).

Palabras-Clave: Variantes maiceras de humedad y temporal, paisaje geográficocultural de altura, conceptuación mesoamericana del mundo.

\title{
Resumo
}

Com base em informações etnográficas, duas variantes agrícolas do sistema sazonal úmido são apresentadas para a região central do México ocupada por uma importante e enigmática jurisdição administrativa e política. Trata-se de El Matlatzinco que abrigou majoritariamente os falantes de quatro línguas otomianas (matlatzinca, otomi, mazahua, e ocuilteco). O território estimado de El Matlatzinco começou a ficar conhecido como 'Vale de Toluca' ainda no século XVI durante o vice-reinado espanhol. A primeira variante da agricultura vem do vale Ixtlahuaca-Jocotitlán, localizado nas zonas serranas daquela região, que foi vinculada, a partir de uma abordagem comparativa, com uma variante na zona lacustre do antigo Matlatzinco. A finalidade é se fazer conhecer duas das técnicas através das quais a agricultura sazonal de milho torna-se adaptada a um ambiente localizado a mais de 2.000 metros acima do nível do mar. Em tais lugares de altitude, onde só é possível uma colheita anual, particularmente por causa das geadas periódicas, o cultivo deve começar antes da estação chuvosa. Contudo, os casos mencionados - em ambas as zonas - ilustram detalhadamente o conhecimento ambiental milenar adquirido pelos habitantes locais e pelos indígenas bem como as limitações ambientais para se obter a umidade necessária para o cultivo dos grãos de milho "sagrados". O artigo também cita as principais festividades relacionadas à agricultura, destacando-se uma em particular devido a suas implicações na forma como a Mesoamérica idealizava o mundo (conceituação de mundo).

Palavras-Chave: variantes do sistema agrícola de milho sazonal úmido, paisagens culturais e geográficas de altura, conceituação Mesoamericana do mundo.

\begin{abstract}
Based on ethnographic information, two variants of the humid-seasonal agricultural system are presented for the central region of Mexico, which is occupied by an important and enigmatic political and administrative jurisdiction. It corresponds to El Matlatzinco, which nested speakers-inhabitants of four Otomian languages (matlatzinca, otomi, mazahua and ocuilteco). The estimated territory of El Matlatzinco began to be
\end{abstract}


known as the Valley of Toluca since early Spanish vice-reign in the sixteenth century. The first agricultural variant comes from the Ixtlahuaca-Jocotitlán Valley - located in the mountainous zone of that region - which we will refer to, from a comparative approach, the variant in the lacustrine zone of the ancient Matlatzinco. The aim of this paper is to describe two maize seasonal agriculture systems adapted to environments over 2,000 meters above sea level. In such high altitude places - where only one annual harvest is possible, especially due to frosts - cultivation must begin before the rainy season. Hence, the cases mentioned in both zones illustrate the detailed millenary environmental knowledge of these inhabitants, and show their environmental limitations in order to obtain the necessary humidity for the cultivation of the corn grain. The study also mentions the main agricultural festivities that are carried out by the Mesoamerican way of conceptualizing the world.

Keywords: maize agricultural system, Mesoamerican.

\section{Introductión}

El Valle de Ixtlahuaca-Jocotitlán comprende un área del Estado de México ${ }^{2}$ perteneciente a la zona serrana o norteña de la región que en el Posclásico ${ }^{3}$ fue ocupada por el Matlatzinco. Éste integró la jurisdicción otomiana -situada al poniente de la cuenca de México- cuyo territorio aproximado empezó a denominarse en los inicios del virreinato: "valle de Toluca"(ALBORES,2006a p.265), entre otros apelativos ${ }^{4}$. El área de Ixtlahuaca-Jocotitlán y la zona lacustre, central o media del antiguo Matlatzinco se ubican arriba de 2,000 msnm (metros sobre el nivel del mar) -y muestran dos de los paisajes geográfico-culturales de mayor altitud en Mesoamérica ${ }^{5}$ - a diferencia de numerosas áreas de la otra zona de aquella jurisdicción -la de cañadas en sierras descendentes o meridional-, que se encuentran por debajo de los 2,000 msnm. Aun cuando en las tres zonas sólo se obtiene una cosecha al año del cultivo del maíz de temporal, la mayor altitud que predomina en las dos primeras zonas ha implicado la

\footnotetext{
${ }^{2}$ El Estado de México es una de las entidades políticas del país que se sitúa en el centro de éste. Figura 1.

${ }^{3}$ Hasta ahora no sabemos con precisión el despliegue territorial y político-administrativo del Matlatzinco ni su cobertura histórica; sin embargo, es posible mencionar de manera tentativa que aquella jurisdicción se integró hacia 1162 n.e. (de nuestra era) y que su quiebre político tuvo lugar, a más tardar, alrededor de 1474 n.e., a raíz de la invasión mexica al Matlatzinco y del sometimiento de la población de éste por la Triple Alianza de la vecina cuenca de México (ALBORES, 2006a, p. 261-262).

"Algunos de los cuales son: "Matalcingo" -castellanización del término náhuatl Matlatzinco-, "valle de Toluca y Matlatzinco" y "valle de Matlatzingo". Sobre los significados con los que se ha utilizado el binomio Matlatzinco/"valle de Toluca", como un concepto histórico, consultar Albores (2006a).

${ }^{5}$ Con el nombre de Mesoamérica, Kirchhoff (1960 p. 7) definió un territorio o "superárea" -donde sus habitantes compartían un sustrato cultural y una historia- que delimitó, para la llegada de los españoles, "desde el río Pánuco al Sinaloa pasando por el Lerma", en el norte, y "desde la desembocadura del río Motagua hasta el Golfo de Nicoya, pasando por el lago de Nicaragua", en el sur.
} 
necesidad de adaptar, en éstas, las respectivas formas agrícolas a ciertas limitantes que imponen las condiciones del entorno natural, debido a que el despliegue anual de las heladas es más amplio que en buena parte de la zona sureña.

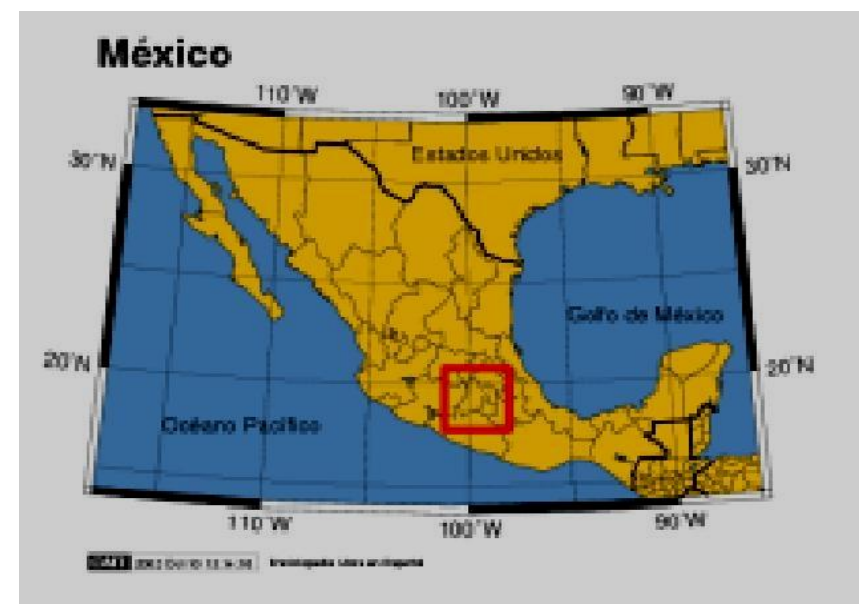

Figura 1- Estado de México

Fuente: Enciclopedia libre http://enciclopedia.us.es/index.php/M\%E9xico [Fecha de consulta 27 de marzo de 2005]

La parte principal del cultivo maicero de temporal ${ }^{6}$ se lleva a cabo en la época lluviosa, correspondiente a una de las mitades o temporadas meteorológicas en que el año trópico de 365.2422 días $^{7}$ ha sido dividido con base en la forma mesoamericana de conceptuar el mundo o conceptuación del mundo ${ }^{8}$ (ALBORES, 2006b p.79). En lo relativo al sistema de temporal, concerniente al cultivo del maíz, Rojas (1991 p.82) indica que "la agricultura que depende de la lluvia estival, por eso llamada en México de temporal, era sin duda la dominante en Mesoamérica", además de que "probablemente ocupaba un área mayor" y donde "se producía la mayor parte del abasto de las poblaciones campesinas prehispánicas".

La población, sobre todo rural y campesina, de las zonas media y septentrional del antiguo Matlatzinco celebran - de manera similar a muchos pueblos del territorio que antaño ocupó Mesoamérica- fiestas o ceremonias religiosas que, siendo común que

\footnotetext{
${ }^{6}$ También llamado "cultivo del maíz de temporal", "ciclo del maíz de temporal" o "ciclo agrícola del maíz de temporal", en referencia al ciclo de cultivo anual del maíz (ALBORES, 2006b p.71).

${ }^{7}$ En cuanto a lo anterior conviene tener presente que, a diferencia del año vago que cubre 365 días, el año trópico abarca cerca de un cuarto de día más. Al respecto, Aveni (1991p.116) señala que el año trópico es el "periodo de revolución de la Tierra alrededor del Sol (o, según los vemos nosotros, del Sol alrededor de la Tierra) con respecto al equinoccio de primavera", que consta de "365.24220 días".
} 
se establezcan a partir del santoral católico, conservan en su mayoría aspectos de raíz mesoamericana, como lo es su vínculo con las principales fases del cultivo del maíz de temporal. Son fiestas que organizan agrupaciones instituidas de cargueros o encargados -que se originaron en los tiempos virreinales-, como veremos en lo relacionado con la fiesta patronal del ejido de Santiago Yeché, que se localiza en el municipio de Jocotitlán. Y también las organizan individuos o corporaciones de especialistas rituales de origen mesoamericano, ya sea paralelamente o de manera articulada con los cargueros. Entre estas últimas corporaciones se encuentran las hermandades de "graniceros" (ALBORES, 2006b p.73) de dos municipios de la zona central del antiguo Matlatzinco. Se trata del municipio de Texcalyacac, donde los graniceros se denominan "quicazcles", y de Techuchulco -perteneciente al municipio de Joquicingo ${ }^{10}$, en el que aquellos especialistas rituales se conocen como "saudinos".

Hasta alrededor de 1980, los quicazcles celebraban anualmente (como aún celebran los saudinos de Techuchulco) cuatro fiestas religiosas obligatorias, a saber, La Candelaria, la Santa Cruz, la Asunción de la Virgen y la Llegada de los Muertos o Muertos. En tres de las cuatro fiestas los quicazcles conducían respectivas procesiones hasta el santuario, ubicado en la cima del volcán Olotepec, donde efectuaban ceremonias relacionadas, en primer término, con el cultivo del maíz de temporal. Las cuatro festividades han sido definidas como "grupo A" (ALBORES, 2006b p.79) e integran, con cuatro celebraciones religiosas más -o "grupo B"-, un "conjunto de ocho fiestas". Éste y, en particular el grupo A, reviste un interesante significado, debido a que su cualidad estructural expresa la forma mesoamericana de conceptuar el mundo o el tiempo-espacio. Es, de manera inicial, el tiempo relativo a dos tipos de ciclos, el meteorológico y el agrícola, que están implicados en el cultivo del maíz de temporal. Y, más ampliamente, es el tiempo cósmico que atañe a los ciclos universales, como veremos.

\footnotetext{
${ }^{8}$ Se trata de una división conceptual con implicaciones distintas, en particular religiosas.

${ }^{9}$ Las palabras y frases entrecomilladas, sin especificación ni referencia bibliográfica, provienen textualmente de los vecinos de la zona norteña y de la zona media del territorio que ocupó el Matlatzinco.

${ }^{10}$ Techuchulco es una localidad -contigua a Texcalyacac- que en 1889 pasó a pertenecer al municipio de Joquicingo (ALBORES, 2000 p.23). Éste y Texcalyacac formaron parte, entre 1900 y 1970 de la zona central del territorio que ocupó el Matlatzinco, junto con 17 municipios más, a saber: Almoloya del Río, Atizapán, Capulhuac, Chapultepec, Lerma, Metepec, Mexicaltzingo, Ocoyoacac, Otzolotepec, Rayón, San Antonio la Isla, San Mateo Atenco, Tenango del Valle, Temoaya, Tianguistenco, Toluca y Xonacatlán.
} 
En el presente trabajo nos referiremos al área de Ixtlahuaca-Jocotitlán, en cuanto a uno de sus dos sistemas agrícolas (que son el de temporal y el de riego) y a algunas de las fiestas conexas, sobre todo las del grupo A. Se enfocan dos cuestiones que aporta el caso de Ixtlahuaca-Jocotitlán, cuyo interés específico radica en lo siguiente. Por una parte, la práctica agrícola que trataremos corresponde a dos formas de la variante local del "sistema de humedad y temporal". Éste ha sido descrito inicialmente en lo relativo al municipio de San Mateo Atenco (ALBORES, 2002) -que pertenece a la zona media del Matlatzinco- con la finalidad de ejemplificar una de las maneras de adecuación del cultivo del maíz a altitudes que rebasan los 2,000 msnm. En este marco, la variante agrícola de Ixtlahuaca-Jocotitlán constituye otra manera en la que el cultivo de temporal ha sido adaptado a dichas altitudes. Son maneras que integran aspectos del conocimiento de origen mesoamericano ${ }^{11}$, los cuales pueden posibilitar una mejor comprensión de la forma antigua de conceptuar el mundo. Por otra parte, los nombres de dos fiestas del grupo A -que encontramos en el área de Ixtlahuaca-Jocotitlán-aluden abiertamente al ciclo del maíz de temporal, lo cual en la zona media del Matlatzinco sólo se pone de manifiesto, sobre todo en la primera fiesta, a través de las respectivas celebraciones religiosas. En la exposición y en el análisis se tendrá como referente a la zona lacustre y, en particular, a los municipios de Texcalyacac, San Mateo Atenco y Joquicingo.

Aunque la población del valle de Ixtlahuaca-Jocotitlán no abarca agrupaciones de graniceros, comparte con los vecinos de la zona central del antiguo Matlatzinco un sustrato otomiano $^{12}$. Asimismo, tiene en común numerosas formas de conocimiento de raíz mesoamericana -como por ejemplo, las de tipo económico, religioso y de la conceptuación del mundo- que muestran aspectos importantes del entorno natural y algunos medios de adecuación de quienes lo habitan, como se mencionó.

\footnotetext{
${ }^{11}$ El conocimiento de origen mesoamericano se expresa en distintas formas -como después veremos de nuevo-, entre las que se cuentan las de tipo: económico, religioso y las relativas a la manera de conceptuar el mundo. La agricultura corresponde a una forma de tipo económico. En la zona media del antiguo Matlatzinco también existió el sistema agrícola de riego en distintas variantes, una de las cuales es la de humedad, que se llevaba a cabo en los "camellones" o "chinampas" del borde de la laguna de Lerma (ALBORES, 1998b).

12 Este sustrato cultural otomiano proviene de la población mesoamericana que habitó, entre otras regiones - como la cuenca de México-, la situada en las sub-cuencas iniciales de los ríos Lerma y Balsas que quedó comprendida en el Matlatzinco del Posclásico (al respecto, consultar ALBORES, 2006b). Los idiomas otomianos son cuatro, como veremos con posterioridad.
} 
El trabajo se basa en datos parciales de la investigación de campo realizada durante 2007, específicamente los provenientes de veinte entrevistas a familias campesinas de las cuatro comunidades que integran el área de estudio. Asimismo se realizaron diversas entrevistas abiertas a un grupo de adultos mayores (hombres y mujeres) para conocer su participación en los rituales agrícolas de la región. El texto se ha dividido en cinco apartados. El primero, denominado El trabajo con el tiempo trata de los especialistas rituales, cuyo quehacer se vincula, de manera importante, con el cultivo del maíz de temporal. El segundo apartado: Contexto geográfico, histórico y cultural, se refiere a la ubicación geográfica del área de estudio en el marco de la región que ocupó el Matlatzinco, enfocándose algunas particularidades fisiográficas e histórico-culturales. El tercer apartado, agricultura tradicional en el área de estudio, da cuenta de las características de una agricultura tradicional de subsistencia que gira en torno al cultivo del maíz de temporal ${ }^{13}$. Se subrayan las características ambientales a las que han debido ajustarse las prácticas agrícolas de temporal en aquella área y en la zona central del antiguo Matlatzinco, mediante respectivas formas de humedad. Y se hace referencia a una de dichas formas, la relativa a la zona central, para introducir lo correspondiente al valle de Ixtlahuaca-Jocotitlán, que se expone en el cuarto apartado. Éste: Cultivo del maíz, prácticas rituales y conceptuación del mundo, se centra en el ciclo agrícola, mencionándose, en cada fase, los rituales que se efectúan y su importancia para los agricultores. Se destaca la tercera fiesta del grupo A con la finalidad de mostrar algunas de sus implicaciones, de particular significación en términos de la conceptuación del mundo. Asimismo se describe la fiesta del titular de Santiago Yeché para ejemplificar el vínculo de las festividades de los Santos Patronos con el ciclo agrícola, como parte de una tradición de raíz mesoamericana. En el último apartado, Las fiestas en cruz del valle de Ixtlahuaca-Jocotitlán, se analizan e interpretan los rituales de la región, con particular énfasis en las fiestas del grupo A, considerándose básicamente los ciclos agrícola y meteorológico. Las conclusiones y la bibliografía cierran el estudio.

\section{El trabajo con el tiempo ${ }^{14}$}

\footnotetext{
${ }^{13}$ A algunas cuestiones teóricas correspondientes se refiere González (2004 p.153).
} 
Los "especialistas rituales del tiempo" comprenden agrupaciones religiosas -e individuos que no pertenecen a corporaciones instituidas- que, como parte de sus deberes principales, anualmente se dedican a propiciar condiciones meteorológicas favorables para que el ciclo del maíz de temporal llegue a buen término (ALBORES, 2006 b p.73). Es decir, entre sus funciones rituales se cuenta el manejo o control del tiempo meteorológico. El logro anual del maíz es primordial puesto que, en la cultura mesoamericana, el grano divino es el fundamento mítico de los mantenimientos del ser humano y de éste mismo ${ }^{15}$, si bien su continuidad también está determinada por su procreación y depende en buena medida de un estado mínimo de salud integral.

Un tipo de especialistas rituales del tiempo está integrado por numerosas corporaciones que reciben el nombre genérico de "graniceros" (ALBORES, 2006b p.74). Éstos habitan distintas regiones alrededor de los volcanes nevados del centro del país: el Nevado de Toluca, el Popocatépetl y el Iztaccíhuatl, donde ocurre una frecuencia significativa de descargas eléctricas. Y es el llamado "golpe del rayo" una forma común por el que los graniceros reciben el don para el manejo del tiempo al ser señalados por Dios y/o por Tláloc, sobre todo en el pasado mesoamericano. Los graniceros han sido parte del entramado religioso que se articula con la forma mesoamericana de conceptuar el tiempo-espacio o conceptuación del mundo. Ésta: a) se refiere a un significado particular de la noción de fecundidad, relativa a un proceso de nacimiento-muerte-resurrección, con base en los mantenimientos y la procreación, y b) tiene que ver no sólo con el origen del ser humano sino también, especialmente, con su continuidad, por lo que en primer lugar alude a los factores que hacen posible la consecución de los mantenimientos.

De manera que, con propósitos de exposición, podemos plantear que, en lo relativo a Mesoamérica, la conceptuación del mundo atañe, inicialmente, al vínculo entre dos tipos de ciclos: el agrícola y el meteorológico, relativos al cultivo del maíz de temporal. Éste se realiza durante el año trópico en sucesivas fases, acordes con las condiciones climático-meteorológicas locales. Así, existen fechas que indican los momentos en que dichas fases o sus etapas deben efectuarse, enlazando al ciclo agrícola

\footnotetext{
${ }^{14}$ Lo relativo a este inciso se trata con mayor amplitud en Albores, (2006b).

15 Al respecto, en uno de los relatos míticos, el Popol vuh (1961p.104), se menciona que de "maíz amarillo y de maíz blanco se hizo su carne", que "de masa de maíz se hicieron los brazos y las piernas del hombre. Únicamente masa de maíz entró en la carne de nuestros padres".
} 
con el meteorológico. Otras fechas señalan celebraciones religiosas que aluden de manera directa o indirecta al ciclo agrícola, por lo que articulan a los ciclos agrícola y meteorológico con el calendario religioso, en particular aunque no únicamente con el católico, como veremos. Entonces, son rituales y festividades agrícolas que se refieren, en primer lugar, al cultivo del maíz que se lleva a cabo año con año (ALBORES, 2006b p.5).

\section{Contexto geográfico, histórico y cultural}

El Matlatzinco y sus zonas geográfico-culturales. El valle de IxtlahuacaJocotitlán ocupa la porción septentrional de la zona serrana, una de las tres mencionadas con anterioridad- en que, de acuerdo con un criterio geográfico-cultural, se ha dividido preliminarmente la jurisdicción del Matlatzinco (ALBORES, 2006a). A la llegada de los españoles en el siglo XVI, el territorio que ocupó esta jurisdicción constituía "el centro de caracterización y de dispersión de los idiomas otomianos" (CARRASCO, 1950 p.283), los cuales son cuatro, como se indicó: matlatzinca, otomí, mazahua y ocuilteco ${ }^{16}$. Numerosos aspectos geográfico-culturales de las tres zonas han sido tratados en trabajos previos ${ }^{17}$, por lo que ahora se mencionará, además de su ubicación dentro de la región, algunos rasgos geofísicos significativos y los principales idiomas, particularmente otomianos ${ }^{18}$, que se hablaban en cada zona en el momento del contacto con los españoles (ALBORES, 2006a). El elemento geográfico-cultural que comparten las tres zonas lo constituye el volcán Nevado de Toluca, que se eleva a 4,256 msnm y es la principal entidad sagrada en la región que ocupó el Matlatzinco, desde

\footnotetext{
${ }^{16}$ Se dejó anotado que el Matlatzinco estuvo poblado mayoritariamente por hablantes de las cuatro lenguas otomianas. Éstos coexistían con gente cuyos idiomas incluían, sobre todo, distintas formas dialectales del náhuatl. Las lenguas otomianas conforman una de las numerosas familias lingüísticas que han existido en Mesoamérica (Soustelle, 1993 p.511-513).

17 Lo concerniente a numerosas diferencias geográfico-culturales de las zonas que conforman el Matlatzinco se ha tratado en varios trabajos. Al respecto puede consultarse Albores (2006a p.264).

${ }^{18}$ De acuerdo con Carrasco (1950 p. 27-28) las lenguas otomianas, de tradición mesoamericana, forman parte del tronco lingüístico otopame. Éste incluye, además, a los idiomas pameanos (pame y chichimeco jonaz, de tradición "nortemexicana"), es decir cazadores recolectores, si bien los pames -o una fracción de éstos -parece que compartieron algunos elementos mesoamericanos. Soustelle (1993 p.511-513) dividió a la familia otomí-pame -en el momento de la llegada de los españoles a Mesoamérica -en dos grupos "de niveles culturales muy diferentes". Así, este autor clasifica a los otomíes, mazahuas, ocuiltecos y matlatzincas, como "agricultores", "sedentarios", y a los pames y chichimeco-jonaces como “cazadores”, nómadas o seminómadas".
} 
tiempos mesoamericanos. Su presencia en las tres zonas les confiere algunas particularidades, como veremos.

Zona meridional. Es de tradición lingüística ocuilteca, en coexistencia con matlatzinca y náhuatl. De tamaño intermedio en relación con las otras dos zonas, se ubica en el alto río Balsas, caracterizándose, en el marco regional, por comprender el mayor abanico altitudinal y climatológico. En efecto, su territorio se desprende desde la cima del Nevado de Toluca hacia el sur, mediante profundas escarpaduras, hasta alcanzar los 1,200 msnm, por lo que también se denomina zona de cañadas en sierras descendentes. Su clima va del frío -en las inmediaciones del Nevado- al relativamente tibio -en el municipio mexiquense de Malinalco-, pasando por el templado. Uno de los montes sagrados más importantes de esta zona sureña es el volcán de Zempoala.

Zona central. De tradición lingüística matlatzinca, en contacto con los idiomas: otomí, mazahua y náhuatl, es la de menor tamaño ${ }^{19}$ de las tres que comprende el territorio que ocupó el Matlatzinco, situándose en la sub-cuenca inicial del río Lerma. Se caracteriza por constituir un valle casi cerrado y por haber contenido en las inmediaciones del Nevado de Toluca al principal depósito acuático de toda la región: la ciénaga o laguna de Lerma, la cual, hasta su desecación hacia 1970, dio origen al río del mismo nombre $^{20}$. Por lo anterior, la zona media también se denomina zona lacustre del antiguo Matlatzinco o del alto Lerma mexiquense ${ }^{21}$, así como "valle de Toluca", en sentido

\footnotetext{
${ }^{19}$ Esta zona mide de largo alrededor de 37 kilómetros -que se orientan de sureste a noroeste, desde las laderas del Nevado de Toluca- por $20 \mathrm{~km}$ de ancho, abarcando unos 740 kilómetros cuadrados (ALBORES, 1995 p.60). Se trata de una zona pequeña si la equiparamos con lo que algunos autores han llamado, en nuestros tiempos, "Valle de Toluca" (SÁNCHEZ,1951) -que mide 4,500 kilómetros cuadrados-, y con la cuenca de México, que cubre 7,850 kilómetros cuadrados, de los cuales, de 800 a 1000 kilómetros cuadrados correspondían a su superficie acuática.

${ }^{20}$ En la zona central del antiguo Matlatzinco existían muchísimos manantiales de agua fría, caliente y templada -situados desde el interior del depósito lacustre hasta las partes montañosas más elevadas-, algunos de los cuales eran particularmente frondosos, como los brazos de agua que surgían en los municipios de Almoloya del Río, Texcalyacac, Xalatlaco y Tianguistengo, así como en Techuchulco, pueblo perteneciente al municipio de Joquicingo, como se mencionó. Entonces, por tratarse de un valle casi totalmente cerrado, el volumen del agua que brotaba y descendía era tan abundante que, acumulándose en el fondo de la planicie, daba lugar a la laguna de Lerma. Ésta se encontraba bordeada de un área cenagosa y, además de "laguna", se conocía localmente como "ciénega" y "lago". Con frecuencia se considera que el río Lerma tiene su origen en los manantiales situados en Almoloya del Río. No obstante, puesto que de toda la zona lacustre emergía y bajaba tal cantidad de agua, como para dar lugar a la laguna de Lerma, es más apropiado señalar a la zona como la progenitora del importante río.

${ }^{21}$ Con base en Chedid (1990), el alto Lerma se ubica en su mayor parte dentro de la entidad mexiquense, integrando el "Alto Lerma mexiquense" (ALBORES, 1998a p.187) y, en menor proporción en
} 
estricto (ALBORES, 2006a p.267). Lo favorable de su entorno natural -en el que el agua y la tierra cristalizaron en una "zona lacustre de altura con volcanes nevados" 22 la convirtió en un foco de atracción humana en todos los tiempos. Así, esta zona "ha sido siempre un cruce de pueblos" - como lo señala Soustelle (1993, p.24)-, con altos índices demográficos desde la antigüedad, según lo indica Giménez (1985 p.246). Una resultante de los aspectos mencionados se observa en el patrón de asentamiento, el cual, en la zona central, ha sido más concentrado que en las zonas meridional y norteña. Concentración que se expresa en la presencia, dentro de la zona, de varios de los municipios más pequeños del Estado de México, como Almoloya del Río, San Antonio la Isla, Rayón, Chapultepec, Texcalyacac y Santa Cruz Atizapán, que en 1950 medían respectivamente 11, 13, 14, 21, 24 y 33 kilómetros cuadrados (FABILA, 1951, v.I, Cartogramas I y II). La laguna de Lerma favoreció el establecimiento de múltiples localidades ribereñas, desde el pasado mesoamericano, a una altitud de alrededor de 2,300 msnm. De manera que, aun cuando esta zona se ubica a los pies del Nevado de Toluca, gran parte de sus pueblos y hasta varias cabeceras municipales se sitúan a menor altura que numerosas localidades de la zona septentrional. Además del volcán nevado, en la zona lacustre existen otros montes que también son objeto de culto local, como el Olotepec, monte sagrado donde se encuentra el santuario de los quicazcles y de los "saudinos" de Techuchulco, como se dejó anotado.

Zona norteña. De tradición lingüística otomí y mazahua, en contacto con matlatzinca y náhuatl. Rodea a la zona lacustre por el occidente y por el norte, dirección que sigue el río Lerma hasta abandonar la entidad mexiquense. Por ello, se la ha llamado preliminarmente "zona norteña" y también, por lo montañoso y abrupto de su paisaje, zona serrana. Su encumbrado relieve da cabida a valles intermontanos -como el de Ixtlahuaca-Jocotitlán-, donde algunas de sus localidades alcanzan la mayor altitud de todos los pueblos situados en el territorio que ocupó el Matlatzinco. De la superficie escabrosa, hendida por barrancas, bajan arroyos que desembocan en el río Lerma, eje hidrológico de esta zona y de la central. La Sierra de las Cruces -que se extiende hacia

Guanajuato, donde finaliza en la presa Solís. En este marco, la zona central del antiguo Matlatzinco integró la zona lacustre del alto Lerma mexiquense.

${ }^{22}$ De hecho, es una de las más altas y húmedas zonas lacustres de Mesoamérica, cuyo paisaje se caracteriza por sus volcanes nevados (ALBORES, 2006b). 
el norte-noroeste en unos 70 kilómetros- y el Monte alto separan de la cuenca o valle de México a la zona central del antiguo Matlatzinco y al valle de Ixtlahuaca. Sus montañas van cortando el Altiplano en pequeños compartimentos y los puertos alcanzan más de 3,000 metros. Entre estas serranías destacan, por su altitud, el cerro de Jocotitlán (con $3,750 \mathrm{msnm}^{23}$ ), así como el cerro de Atlacomulco (que rebasa los 3,000 msnm) y otras prominencias más (AHA, caja 207, exp. 1798, fojas 4-5, agosto, 1948 en REYES, 2006 p.26).

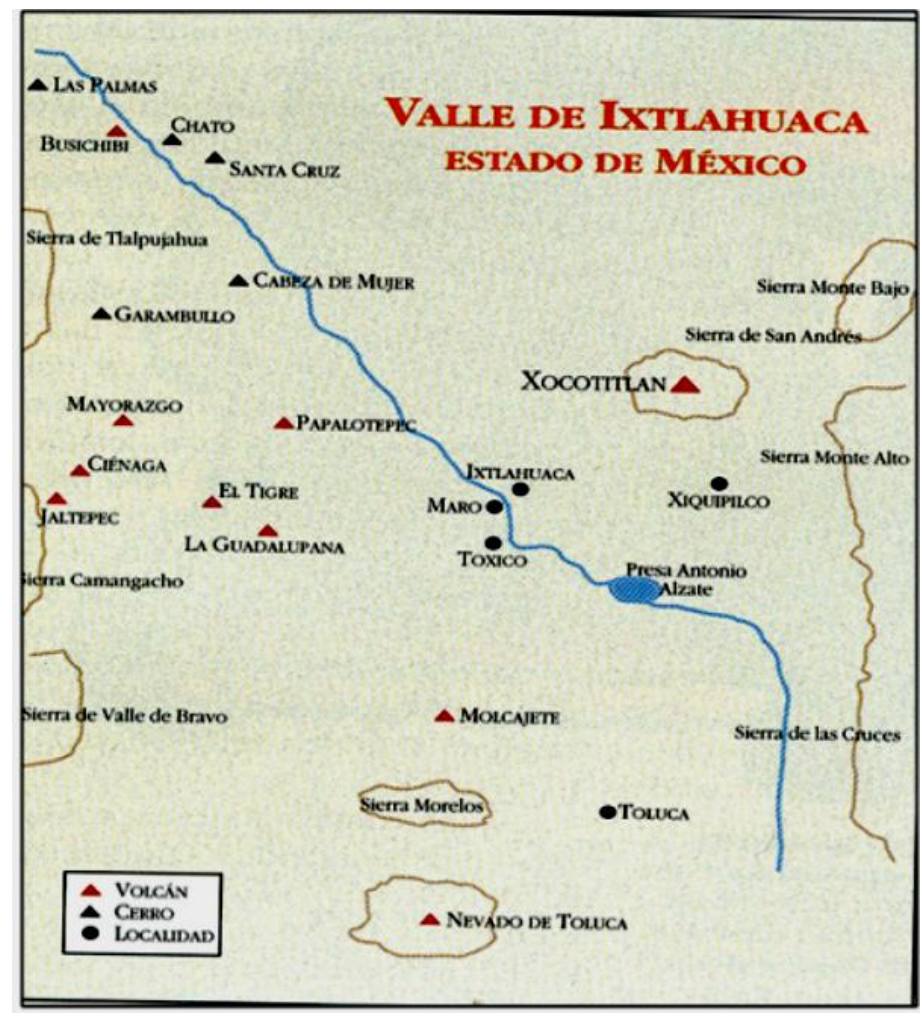

Figura 2: Zona norteña

Fuente: María de los Ángeles Velasco Godoy, 2003.

Basada en Enciclopedia de México. Ilustración digital: Raíces.

La zona norteña, como la zona meridional, requiere ser subdivida (con base en estudios específicos), si bien en el marco regional se caracteriza por lo escarpado -como se anotó- de su superficie. Además del Cerro de Jocotitlán, existen otros cerros pequeños como San Miguel Tenochtitlán, Santiago Casandeje y el monte sagrado de Santa Cruz Tepexpan.

\footnotetext{
${ }^{23}$ Según Ramírez (2005) La única altura importante en el valle de Ixtlahuaca es el Xocotépetl, o cerro de Jocotitlán, de 3,952 msnm, en cuya falda se asienta la cabecera municipal de Jocotitlán. El resto es valle. El cerro de Jocotitlán está considerado como reserva ecológica llamada parque estatal Isidro Fabela.
} 
A la llegada de los españoles, si bien la agricultura era la actividad básica de los otomianos, los trabajos no-agrícolas constituían una parte importante de su economía. Así, la recolección y la cacería -terrestre y aérea- eran de particular significación, sobre todo en las zonas norteña y meridional de aquella jurisdicción, en tanto que dichas actividades, de recolección y caza, en sus variantes acuáticas, además de la pesca, caracterizaban el trabajo de los habitantes de la zona central, que éstos desplegaban, en buena medida, en la laguna de Lerma (ALBORES, 1998a, 2006a). Junto al fuerte peso de las actividades no-agrícolas -que le confiere un matiz distintivo a la cultura otomiana del antiguo Matlatzinco-, existe otro aspecto relevante, de carácter agrícola: la costumbre de cosechar y consumir mayoritariamente el fruto tierno del maíz: los elotes (SAHAGÚN, 1956, t.III p.198). Se trata de dos especificidades culturales de los otomianos a partir de las cuales fueron estigmatizados por los mexica, en el marco de la invasión de la Triple Alianza al Matlatzinco y del sojuzgamiento de su población otomiana, desde el último cuarto del siglo XV (ALBORES, 1985).

El área de estudio ${ }^{24}$. Los ejidos de Santiago Yeché (Meje), San Francisco Chejé, San Juan y San Agustín (Tiacaque) y Santa María Del Llano se asientan dentro del valle de Ixtlahuaca-Jocotitlán ${ }^{25}$-en el noroeste del Estado de México-, que pertenece a la zona norteña o serrana, como se indicó. Este valle queda comprendido -de los $19^{\circ} 34^{\prime}$ a los $19^{\circ} 52$ de latitud norte y desde los $99^{\circ} 40^{\prime}$ hasta los $100^{\circ} 05^{\prime}$ de longitud oeste-, entre Ixtlahuaca de Rayón y Atlacomulco (GUTIÉRREZ, 1979 p.9 en REYES, 2006 p.25). Se localiza en seguida de la zona lacustre del alto Lerma y, además de los municipios de Ixtlahuaca y Jocotitlán, abarca porciones de Jiquipilco, que se sitúa al oriente del primer municipio y al sur del segundo. A diferencia de la zona lacustre, que constituye un valle casi totalmente cerrado, como se mencionó, el valle de Ixtlahuaca-Jocotitlán es un "valle abierto" (Gutiérrez, 1979 p.9) -que corre, como la zona lacustre, de sureste a

\footnotetext{
24 En el presente trabajo utilizamos los conceptos de "región", "zona" y "área" como conceptos territoriales de mayor a menor extensión, respectivamente, además de que, en el caso de los dos primeros, tienen implicaciones lingüístico-culturales.

${ }^{25}$ A excepción de Santa María del Llano, que se encuentra en el municipio de Ixtlahuaca, el resto de los ejidos pertenecen al municipio de Jocotitlán.
} 
noroeste-, conformado por una planicie alargada, a la cual drena el río Lerma ${ }^{26}$, como se ha apuntado.

El área de estudio ha contenido población mazahua y otomí. Así, en el siglo XVI se hablaba mazahua en Ixtlahuaca y Jocotitlán y ambas lenguas en Xiquipilco Jiquipilco- (CARRASCO, 1950 p. 29-30), las cuales en el siglo XVII se han reportado no sólo acá sino también en Jocotitlán (SOUSTELLE, 1993, Mapa V). No obstante, este último e Ixtlahuaca figuraban, en la segunda década del siglo $\mathrm{XX}$, dentro de los "10 municipios habitados por mazahuas de manera masiva", como fue anotado por Soustelle (1993 p. 270-269), quien señaló que "la región de Ixtlahuaca todavía constituye el centro del país mazahua", en tanto que Jiquipilco ya sólo formaba parte del "territorio otomí”. En el siglo XV, el valle de Ixtlahuaca-Jocotitlán sufrió la invasión y el dominio mexica como parte de su expansión, con base en la vía armada. En el siglo XVI y primera mitad del siglo XVII tuvo lugar la conquista y ocupación españolas.

Los pobladores otomianos han adaptado sus prácticas económicas, de origen mesoamericano, a las características del medio natural del área de estudio, procurando manejar de manera equilibrada los recursos disponibles, en particular el agua y la tierra. Marco en el que siguen practicando la agricultura que es en nuestros tiempos el sostén, básicamente cultural, de su subsistencia. Así, los indígenas de la región establecen determinados espacios donde llevan a cabo, además de la agricultura, otras actividades, como turismo ecológico (caso de Tiacaque) y la fabricación de carbón.

\section{La agricultura tradicional en el área de estudio}

La agricultura en el valle de Ixtlahuaca-Jocotitlán -de una fuerte raíz mesoamericana- es tradicional ${ }^{27}$, es decir, se trata de una agricultura de subsistencia que gira, como se ha mencionado, en torno al cultivo del maíz de temporal. Con respecto a lo anterior, "el campesino -anota Mariaca (1997 p.16-17)- aplica los conocimientos heredados de sus raíces mesoamericanas" y algunos "métodos españoles traídos durante

${ }^{26}$ El río Lerma, de aguas permanentes, corre localmente con dirección sureste a noroeste y es el colector de las aguas que llevan pequeños arroyos, cuyo nacimiento se encuentra en los cerros que limitan el valle. Esta corriente fluvial desciende hasta alcanzar la Laguna de Chapala para, posteriormente, proseguir con el nombre de Santiago o Río Grande y desembocar en el Océano Pacífico (AHA caja 207 exp. 1798 foja 5, agosto 1948, en REYES, 2006 p.28). 
el período colonial". Además incorpora ciertas "técnicas consideradas como modernas" y "sus propias innovaciones", con lo que se ha "configurado una forma de hacer agricultura con características específicas" en lo correspondiente a las regiones respectivas, a la que el autor ha denominado "tradicional o agricultura de subsistencia"28. Así, aun cuando en el área de estudio encontramos porciones de riego, la mayoría de las tierras son de temporal, por lo que su cultivo tiene como referente básico la alternancia entre la temporada de secas y la de lluvias, a partir de la cual se organiza no sólo la actividad agrícola sino también la ceremonial, como pudo observase en la investigación de campo, en el valle de Ixtlahuaca-Jocotitlán.

De las distintas formas del sistema agrícola $^{29}$ de temporal, éste ha sido adaptado, en el valle de Ixtlahuaca-Jocotitlán, a una variante de humedad y riego. Como sistema de temporal, pertenece al tipo de explotación agrícola "orientada hacia el autoconsumo"30 y, de acuerdo con la clasificación de Palerm (1971), corresponde al de barbecho $^{31}$. El sistema de humedad y temporal comprende dos formas en el área de estudio, la que además cuenta, como se dejó anotado, con sistema minoritario de riego. Ambos sistemas están adaptados al declive, a la calidad del suelo y al agua disponible del lugar. Es decir, desde el punto de vista de las condiciones ambientales en las que los dos sistemas agrícolas se encuentran y se ajustan, cada uno representa un nivel de adaptación o control del ambiente (REYES, 2006 p.100). La agricultura de humedad y temporal de los ejidos de Santiago Yeché (Meje), San Francisco Chejé y buena parte de Tiacaque (que incluye a San Juan y a San Agustín) se practica en terrazas, aun cuando en una porción reducida de Tiacaque y en Santa María del Llano se efectúa en la planicie, donde también se recurre parcialmente al riego.

\footnotetext{
${ }^{27}$ El término de agricultura tradicional corresponde a dos sistemas agrícolas de origen mesoamericano: de temporal y de riego (ROJAS, 1985 t.I p. 132).

28 Las denominaciones de agricultura tradicional y agricultura de subsistencia -aunque constituyen un punto teórico a discutir- nos permiten enmarcar ciertas particularidades de la agricultura en el valle de Ixtlahuaca-Jocotitlán. Según Mariaca (1997) y su postura teórica Xolocotziana, parte de la explicación sobre la relación entre el agricultor y el ambiente, se basa en primer lugar en no considerarla estática sino como un proceso dinámico y que varía tanto espacial como temporalmente.

${ }^{29}$ Rojas (1991p.46) señala que "el concepto de sistema agrícola es una abstracción construida a partir de la consideración de las técnicas básicas de manejo", así como "de la intensidad agrícola".

${ }^{30}$ El término autoconsumo indica que la actividad productiva se orienta exclusivamente al cultivo de productos de subsistencia, como el maíz, destinándose principalmente a satisfacer las necesidades alimenticias de los productores y sus excedentes, que por lo general son mínimos, se canalizan a los mercados locales y regionales para su venta.
} 
En las latitudes tropicales del norte, en las que se ubica el territorio que ocupó Mesoamérica, la época lluviosa ocurre en general de mayo a octubre, dentro de la cual se lleva a cabo el cultivo del maíz en los predios que se trabajan mediante el sistema agrícola de temporal. En este contexto, cabe considerar que la altitud sobre el nivel del mar puede limitar el periodo de realización del sistema agrícola mencionado, por lo que el comienzo de éste depende fundamentalmente de las características del entorno natural en las que se efectúa la actividad agrícola. Así, es importante tener en cuenta que, a partir de dichas características es posible, como veremos: a) paliar ciertas constricciones que determina una altitud considerable -como las relativas al área de estudio-, mediante técnicas específicas o de los momentos en los que éstas se efectúan, y b) emplear algunas variedades maiceras. Ahora bien, ya se indicó que, conceptualmente, la tradición de origen mesoamericano establece dos épocas dentro del año trópico: lluviosa y seca, mismas que se marcan mediante fiestas religiosas que contienen un fuerte trasfondo cultural de la antigua superárea.

En este contexto, las unidades domésticas campesinas del valle de IxtlahuacaJocotitlán cultivan en pequeña escala (de $1 / 2$ a 2 hectáreas). Y, como veremos después con mayor amplitud, se procura minimizar los riesgos con determinadas medidas, entre las que destaca la roturación temprana de los suelos para iniciar el ciclo agrícola con el tiempo suficiente para que concluya antes del advenimiento de la temporada de heladas. También se recurre a los cultivos mixtos, al uso de variedades resistentes al frío y al empleo, en lo posible, de parcelas fragmentadas (unas de riego y otras de temporal). Se procura, además, reducir máximos de las demandas de mano de obra con cultivos diversificados, así como combinando variedades de simiente de maduración rápida y prolongada. En resumen, en el área de estudio la agricultura tradicional se realiza de acuerdo a las características ambientales y, de manera fundamental, con base en su herencia cultural de origen mesoamericano.

Sistema agrícola de temporal y sus formas de humedad. Se mencionó que en el valle de Ixtlahuaca-Jocotitlán -al igual que, en general, en la zona norteña del antiguo Matlatzinco- y en la zona lacustre del territorio que ocupó la jurisdicción del Posclásico, sólo es posible obtener una cosecha de maíz de temporal al año. Y si ello

${ }^{31}$ El sistema de barbecho es conocido en México como de descanso, alternando los campos de cultivo o 
también es cierto para la zona meridional -donde existen áreas situadas un poco más arriba de los 1,000 msnm-, en las dos primeras zonas, el poder realizar únicamente un cultivo anual ha requerido respectivos procesos de adecuación técnica. Esto es, para enfrentar las heladas, que constituyen la principal limitante climática en las altitudes donde se encuentran la zona lacustre -cuyas partes más bajas llegan a alrededor de 2,300 msnm- y el valle de Ixtlahuaca-Jocotitlán -donde algunas porciones de su territorio alcanzan casi los 3,000 msnm. Las otras limitantes son el granizo y aun la lluvia que, en ciertas circunstancias, pueden poner en peligro a los plantíos.

En las zonas septentrional y media (y en la parte más norteña de la zona meridional) las heladas se presentan de noviembre a marzo, pero algunas se adelantan desde el inicio de octubre y aun en septiembre, mientras que otras, tardías, llegan a ocurrir a fines de mayo. Así, el ciclo agrícola se efectúa tomando en cuenta las particularidades ambientales, por lo que la siembra en general se realiza entre el 19 de marzo y el 15 de mayo, es decir, entre las fiestas de San José (19 de marzo) y de San Isidro Labrador (15 de mayo), con las que ritualmente se señala, de manera respectiva, el inicio y el fin de la fase de siembra (ALBORES, 2002 p. 253-254).

En este marco, es posible distinguir dos grupos de cultivadores: los "marceños" -que siembran del 19, 20 o 21 de marzo hasta fines de este mes- y los no-marceños que plantan desde los primeros días de abril hasta el 15 de mayo. No obstante existen campesinos que siembran en la época marceña y en la no-marceña.

Los marceños dan un margen de tiempo para que la cuajadura del fruto suceda antes de que alguna helada tempranera ocasione defectos en la maduración, aunque se arriesgan a la pérdida de su plantío si acaece una helada tardía cuando empieza el crecimiento de la planta. Considerando lo anterior, los no-marceños cuentan con cierta ventaja. Si se planta después del 15 de mayo -pudiéndose, teóricamente, sembrar hasta antes del 25 de mayo- algunas lluvias tempraneras, si son muy abundantes causan un crecimiento demasiado rápido de la planta -dificultando su jiloteo-o, de ocurrir éste, el mayor riesgo radica en una precaria granazón de la mazorca por el advenimiento de los fríos. Por otra parte, las heladas anteriores a la cosecha del fruto maduro resultan benéficas debido a que matan la hierba que crece en la milpa, con lo que el cultivador no tiene que efectuar el último desyerbe, lo que facilita la realización de la cosecha. 
Entonces, a partir de las limitantes que imponen las heladas, la siembra debe efectuarse antes del inicio de la época lluviosa, la cual, en términos religiosos y conceptuales está delimitada -dentro del territorio que ocupó el Matlatzinco- por las fiestas de la Santa Cruz, al inicio de mayo, y la Llegada de los Muertos, al comienzo de noviembre (ALBORES, 2006b p.81). Entonces, si, como acabamos de ver, la siembra tiene lugar desde marzo, los cultivadores deben contar con una mínima humedad en sus campos de labor. La forma como los agricultores han resuelto esta cuestión crucial nos muestra el profundo conocimiento del medio natural para, como se mencionó, adecuar la agricultura a las particularidades prevalecientes en cada espacio territorial, ya sea éste de mayor o menor altitud.

En cuanto a la zona lacustre del alto Lerma mexiquense trataremos el caso correspondiente al municipio de San Mateo Atenco. Éste ejemplifica a los pueblos ribereños contenidos por la cadena de montes - que a manera de cinturón cercan la zona casi en su totalidad-, entre los cuales destaca el volcán Nevado de Toluca. Los vecinos de Atenco construyeron desde tiempos mesoamericanos ${ }^{32}$ las llamadas "zanjas" o "escurrideras" a todo lo ancho del municipio que, comenzando en la parte territorial más elevada, desembocaban en la laguna de Lerma. La finalidad de este sistema de canales era conducir hasta la ciénaga el agua que descendía de las montañas circundantes (ALBORES, 2002), en particular el agua de la nieve de la cima del Nevado de Toluca y, en el pasado, también de algunas partes de la sierra circundante- que se derretía, sobre todo, en la etapa más caliente dentro de la mitad seca del año ${ }^{33}$.

A una altura superior a 2,000 msnm, la época de heladas -que se extiende en general, como lo indicamos, de noviembre a principios de marzo- es seguida por la etapa más calurosa de la temporada seca anual. Esta etapa ocurre alrededor del equinoccio de primavera coincidiendo, en términos religiosos, con la conmemoración católica de la Semana Santa, que tiene lugar en la primera luna llena después del equinoccio. En cambio, en altitudes menores a 2,000 $\mathrm{msnm}$-específicamente en las que se encuentran por debajo de los 1,000 msnm- dicha etapa se amplía, pudiendo delimitarse desde el inicio de la Cuaresma -que comienza al día siguiente del Miércoles de Ceniza- hasta el Domingo de Resurrección, con el que se cierra la Semana Santa.

\footnotetext{
${ }^{32}$ Tiempos sobre los cuales sólo se sabe, localmente, que son inmemoriales.

${ }^{33}$ Es la etapa más calurosa de la mitad o época seca del año trópico.
} 
Así, el agua que descendía hasta la ciénaga, se desbordaba de los canales e inundaba los campos de labor, proveyéndolos de la humedad suficiente para que los campesinos de Atenco emprendieran la siembra marceña, la cual es más precisamente equinoccial, pues su comienzo se indicaba por ese acontecimiento solar -que generalmente ocurre entre el 19 y el 21 de marzo- y concluía a fines de este mes, como vimos. También los no-marceños contaban con la humedad ocasionada por el agua que bajaba de los montes cercanos y del propio Nevado, desde la etapa que se ubica entre el equinoccio de primavera y la semana santa. Esto es, considerando que ésta puede ocurrir desde la misma semana en que tiene lugar el suceso astronómico hasta después de alrededor de 30-35 días de su acaecimiento, o sea, hasta la fiesta de San Marcos. Al respecto, es muy interesante que dicha celebración (que tiene lugar el 25 de abril) forme parte, en varias regiones de la antigua Mesoamérica -entre las que se cuenta el territorio que abarcó el Matlatzinco-, del lapso festivo de la Santa Cruz, cuando se inicia, ritualmente, la temporada lluviosa o húmeda del año trópico, como se indicó.

En los cuatro ejidos del valle de Ixtlahuaca-Jocotitlán, sus pobladores recurren a una manera distinta para abastecer de humedad a sus terrenos de siembra, como veremos un poco más adelante. Además, en los predios de la planicie se capta anualmente agua de lluvia, en pequeños depósitos, para irrigar la milpa en caso necesario. De manera que la zona lacustre y el valle de Ixtlahuaca-Jocotitlán ejemplifican dos variantes de humedad del sistema de temporal.

\section{Cultivo del maíz, prácticas rituales y conceptuación del mundo}

En las cuatro comunidades del área de estudio existe una fuerte tradición religiosa, de origen mesoamericano, relacionada con la agricultura y con el calendario cristiano que se introdujo desde los inicios de la evangelización ${ }^{34}$. A través de la práctica agrícola y de las festividades religiosas conexas -en especial las del grupo A- se destacarán algunos aspectos: a) del medio natural, en cuanto a similitudes y diferencias con respecto a la zona lacustre del alto Lerma mexiquense, así como en lo que atañe a la manera cultural de adaptación a las especificidades ambientales y b) en lo relativo a las particularidades de la tercera fiesta del grupo A en el área de Ixtlahuaca-Jocotitlán.

\footnotetext{
${ }^{34}$ Es posible observar algunos elementos que recuerdan al "catolicismo del siglo XVI", como, "por ejemplo la utilización de cruces protectoras en campos cultivados e intersecciones de caminos" (GONZÁLEZ, 2004).
} 
Lo referente al cultivo del maíz de temporal, en el valle de Ixtlahuaca-Jocotitlán, ha sido dividido para su exposición en cinco fases -con varias etapas-, que son: A) Preparación del terreno, B) Siembra, C) Abonamiento, escarda y deshierbe, D) Cosecha y E) Corte y almacenamiento del rastrojo ${ }^{35}$, a las que nos referiremos a continuación.

A) Preparación del terreno. Ésta es la fase en la que los campesinos proveen a sus predios de labranza de la humedad necesaria para poder sembrar desde antes del inicio de la temporada lluviosa. Los ejidos del valle de Ixtlahuaca-Jocotitlán no cuentan con agua de deshielo que descienda en cantidad equiparable a la que recibía San Mateo Atenco, particularmente por el derretimiento del hielo de la cima del volcán Nevado de Toluca $^{36}$. No obstante, la altitud media de los municipios de Ixtlahuaca (2,640 msnm) y Jocotitlán $(3,000 \mathrm{msnm})^{37}$ propicia una ocurrencia mayor de heladas que en los pueblos ribereños de la zona lacustre, donde también son menos intensas que en los ejidos. Acá, de las heladas -que se presentan entre noviembre y marzo, como se indicó-, las más fuertes son generalmente las nocturnas y, en particular, las que acaecen en la etapa de máximo frío que abarca de diciembre a febrero. De manera que, el agua del entorno que se congela, durante la noche, se derrite con el sol diurno. Este fenómeno es aprovechado por los agricultores mediante una temprana roturación del terreno (como también se mencionó). Por una parte, con la sola roturación se amplía la superficie que, por la noche, retiene el agua congelada y, además, se conserva mejor la humedad, al abrirse la tierra. Y, si a ello, se aúna la ampliación del lapso en el que se efectúa la apertura de la tierra, se favorece que ésta acumule mayor humedad. Al agua que se obtiene por el medio antes descrito se le aúna la que proviene de las lloviznas que caen de manera ocasional $^{38}$.

En el valle de Ixtlahuaca-Jocotitlán se acostumbra preparar el terreno en los meses de enero a febrero, si bien algunos agricultores de edad avanzada realizan esta fase desde diciembre, para dar lugar, como se señaló, a una acumulación más alta de

\footnotetext{
${ }^{35}$ Fases establecidas con base en Albores (2002).

${ }^{36}$ Se habla en pasado: "recibía" debido a que en los últimos tiempos el Nevado de Toluca tiene cada vez menos hielo en su corona.

${ }^{37}$ Los datos proceden de Fabila (1951, vol. I, cuadro II). En Ramírez (2005 p.225-254) se anota que los municipios de Ixtlahuaca y Jocotitlán se ubican, respectivamente, a 2,500 y 2,900 msnm.

${ }^{38}$ La información concerniente a la forma de captar humedad en el valle de Ixtlahuaca-Jocotitlán, reunida de diciembre de 2007 a enero de 2008, se complementó con los datos recopilados, de manera específica,
} 
humedad en el suelo. Costumbre que, al parecer, era generalizada con anterioridad, cuando económicamente se dependía más del cultivo del maíz.

Las prácticas para humedecer los terrenos de labor, que llevan a cabo los campesinos de Atenco y del valle de Ixtlahuaca-Jocotitlán, permiten adelantar la fase de siembra a la vez que muestran los medios que han inventado los respectivos pueblos para adecuar sus prácticas económicas, específicamente las agrícolas, a las particularidades del entorno natural inmediato. De no haberlas ideado, el inicio de la fase de siembra tendría que esperar hasta la llegada del temporal lluvioso, con lo que sería difícil realizar el cultivo del maíz en estas tierras altas, frías, sobre todo las del valle de Ixtlahuaca-Jocotitlán. Acá, las lluvias empiezan en mayo o, si se presentan tarde, en junio (Entrevista No. 7, mayo de 2007). Por lo anterior, los respectivos métodos de labranza constituyen variantes del sistema agrícola de humedad y temporal y, como veremos, el caso del valle de Ixtlahuaca-Jocotitlán presenta una adecuación más, como se ha señalado, en cuanto al acopio de agua para las etapas subsecuentes del ciclo agrícola.

En el valle de Ixtlahuaca-Jocotitlán la preparación del terreno se realiza en tres etapas, siendo la primera el barbecho ${ }^{39}$. Consiste en aflojar el terreno, volteando la tierra para que la humedad comience a acumularse. Luego viene la "segunda" -como se nombra a la etapa que sigue al barbecho-, en la que se rotura el suelo más profundamente para aumentar la concentración de la humedad. Y, por último, la "rastra", que se efectúa a fines de febrero o a principios de marzo, pasándose sobre el campo de labor una viga pesada - jalada por bueyes o caballos- para desbaratar los terrones y compactar la superficie del terreno, a fin de evitar que éste se reseque por la evaporación del agua acumulada. El objetivo es, entonces, emparejar la tierra para que retenga la humedad que se ha generado. Así, después de prepararlo, el terreno queda listo para que en el mes de marzo se proceda a formar los surcos, a abonar y a sembrar.

en la cabecera del municipio de San Felipe del Progreso -situado al poniente de los municipios de Ixtlahuaca y Jocotitlán- en diciembre de 2008.

${ }^{39}$ Con el término "barbecho" se nombra a la fase con la que se emprende la fase inicial del ciclo agrícola, además de emplearse en la clasificación de los sistemas agrícolas de temporal, en referencia al descanso en que se deja a los terrenos de labor. Al respecto, en el área de Ixtlahuaca-Jocotitlán y en la zona lacustre del alto Lerma se utiliza el mismo término: "barbecho" en referencia a la primera roturación del terreno de labor, aun cuando en aquella área se acostumbra dejar en descanso a los predios y en la zona lacustre no, sino que se cultivan año con año. 
Actualmente, la primera fase del ciclo agrícola se realiza en la mayoría de los casos con tractor y sólo algunos campesinos utilizan la yunta.

En cuanto a las prácticas rituales, dentro de esta fase del ciclo agrícola se efectúa la fiesta religiosa del 6 de enero en el santuario de la Capilla (del municipio de Jiquipilco), perteneciente al valle de Ixtlahuaca-Jocotitlán. Es una celebración que en Mesoamérica, en general, forma parte de un lapso festivo que empieza con la fiesta del 24 de diciembre - en la que se celebra el nacimiento del niño Dios- y termina con la conmemoración de la virgen de la Candelaria, el 2 de febrero. Localmente, la fiesta de diciembre parece marcar el fin de la última fase agrícola, en tanto que la de febrero se vincula con el grano que está por sembrarse, como veremos en seguida.

Bendición de la simiente. La primera fiesta del grupo A es "la bendición de las semillas", el 2 de febrero - día de la Virgen de la Candelaria ${ }^{40}$-, que señala el inicio ritual del ciclo agrícola de temporal, el cual ha comenzado con la preparación del terreno, desde enero o aun en diciembre. En este marco, dicho inicio hace énfasis en el grano que está por sembrarse, a diferencia de las fiestas del 24 de diciembre y del 6 de enero, que tienen lugar cuando, respectivamente, finaliza la cosecha y el trabajo agrícola está centrado en el terreno de labor. El nombre de la fiesta del 2 de febrero (que forma parte del grupo A) se refiere directamente al ciclo agrícola de temporal, aun cuando, en términos católicos, está dedicada a la virgen de la Candelaria, pudiendo observarse la preeminencia de un aspecto de origen mesoamericano, relativo al cultivo del maíz.

Los campesinos del valle de Ixtlahuaca-Jocotitlán acostumbran llevar a bendecir a la iglesia la simiente -simbolizada en una mínima parte de ésta- que sembrarán ese año, sobre todo de maíz, así como de frijol, haba, papa, chícharo, trigo, cebada y calabaza. Con tal finalidad seleccionan cuatro o siete mazorcas de maíz - entre el final de la cosecha y la festividad del 2 de febrero- y las colocan en el centro de una canasta junto con el resto de las semillas y una imagen del niño dios o cualquier otra imagen, como un cristo o una virgen. Generalmente, es la mujer la que adorna la canasta con flores y una servilleta blanca y bordada (Observación febrero 2007). Después de la misa, el sacerdote efectúa la ceremonia de "bendición de las semillas", las cuales indica el párroco de Santiago Yeché- “junto con las imágenes, están simbolizando 
fertilidad" es decir, los campesinos relacionan la imagen del niño Dios con el maíz (Entrevista, mayo 2007). Al finalizar la ceremonia, la canasta es colocada en el altar de la casa-habitación -al lado de una imagen religiosa, flores y veladoras-, donde se conserva hasta la llegada de la siembra. Entonces, las mazorcas bendecidas se desgranan, la semilla se revuelve con el resto de la simiente, previamente seleccionada, que se plantará durante el ciclo agrícola. Los "olotes" se entierran en uno de los surcos (Entrevistas, mayo 2007).

En la zona lacustre del territorio que ocupó el Matlatzinco, la designación de la fiesta -que se realiza en las fechas pareadas del $1^{\circ}$ al 2 de febrero o sólo en la última fecha-: "Día de la Candelaria" o "La Candelaria" no hace referencia directa al ciclo agrícola, como sí ocurre en el valle de Ixtlahuaca-Jocotitlán. En efecto, en este valle la fiesta del 2 de febrero se llama "La bendición de las semillas", como vimos en los párrafos anteriores. Esta fiesta siguió efectuándose el día 2 del calendario juliano, si bien corresponde al 12 de febrero, a partir de la reforma gregoriana de 1582. El día 2 el cura bendice distintos elementos que habrán de emplearse en el transcurso del año, entre los cuales se encuentra una parte de la simiente que, en San Mateo Atenco, se ha sacralizado por vez inicial el $1^{\circ}$ de enero. Simiente bendita que se mezcla con el resto de las semillas para utilizarse en el ciclo agrícola que está comenzando. Se pide por el buen desarrollo de éste y se lleva a cabo, con un fuerte carácter ritual, la siembra minoritaria -de maíz, haba y calabaza, sobre todo- en predios que, aun siendo de humedad, se cultivan mediante el sistema de temporal ${ }^{41}$. El mismo día 2 de febrero se bendice una serie de propiciadores que usarán los quicazcles (de manera especializada) y los vecinos (en forma no especializada) para que, entre otros fines, ocurra una lluvia favorable o para ahuyentar los vientos huracanados y el granizo que pueden dañar a los sembradíos, a veces de manera irreparable. En fin, el 2 de febrero "se saca" a "oír misa" al niño

${ }^{40}$ El párroco de Santiago Yeché, señala que Candelaria significa Candela o vela y es la fiesta de la presentación de nuestro señor Jesucristo, es decir "la candela simboliza a Cristo" (Entrevista mayo 2007).

${ }^{41}$ Sobre lo anterior, consultar a Rojas (1985, t.IP.132, negrillas: B.Albores y L. Reyes) quien menciona que "Tras la antigua y ya tradicional forma de diferenciar la agricultura según la fuente de aprovisionamiento de la humedad en temporal, humedad y riego" se expresan "las diferencias en la intensidad agrícola" como "los sistemas intensivos, ya sea anuales o continuos, y los de temporal" mismos que, "rara vez lo fueron de tipo intensivo. Ello no descarta" que "algunos sistemas de temporal fueran más intensivos, bien porque se daban condiciones naturales excepcionales" o por "arte del trabajo humano que acondicionó [...] el terreno". Así, desde tiempos mesoamericanos, además del sistema agrícola de temporal, existe el sistema de riego, de importante trascendencia en la superárea. Se dejó anotado que en la zona lacustre de la región que ocupó el Matlatzinco, dos de las formas agrícolas que se practicaron son la de humedad y temporal y la de humedad y riego (ALBORES, 1998b, 2002). 
Dios, después de que se "levanta" y se "sienta", el 6 de enero, y de haber sido "arrullado", estando acostado, el 24 de diciembre. En la zona lacustre, las dos últimas fechas (de diciembre y enero) forman parte de los últimos marcadores rituales de la cosecha del maíz seco, después de la cual puede emprenderse la preparación del terreno para el nuevo ciclo, en el mismo mes de enero. Ahora bien, en términos del grano, en la fiesta de diciembre se alude al goce del fruto macizo -que habrá de destinarse en su mayoría a la alimentación humana-, en cambio, en la celebración de febrero se hace hincapié al grano duro como simiente con el que se iniciará el ciclo agrícola.

\section{B) Siembra}

La siembra comprende las etapas de: escogimiento de la simiente, rayado, surque, hechura de cabeceras, abonamiento y sembradura o siembra, en sentido estricto.

El escogimiento de la semilla -que será sembrada, no la que se lleva a bendecir, el 2 de febrero- puede efectuarse en cualquier momento entre la cosecha y la siembra. De acuerdo con los vecinos del valle de Ixtlahuaca, acá se siembra, entre otras, maíz de semilla blanca, negra y amarilla, destinándose, esta última, para alimentar a los animales que se crían en la casa. Por lo general, la simiente no se compra sino que se obtiene del maíz cultivado el ciclo anterior. Antes de sembrar se efectúan, con yunta, los trabajos siguientes: "rayar" -abriendo líneas paralelas: las rayas, en el terreno de laborpara luego "echar los surcos" o "surquear", demarcando líneas transversales a las rayas, y, por último abrir las cabeceras en los extremos del terreno para dar salida, eventualmente, al agua pluvial (Entrevista No. 6, mayo 2007). Después viene el abonamiento, con productos de origen orgánico o químico -denominado "18-46"- y en seguida se lleva a cabo la siembra, en sentido estricto, para la cual se utiliza ya sea tractor o yunta jalada con animales de tiro, aun cuando ésta es empleada sólo por una minoría. Así, en la tierra húmeda, recién abierta, los sembradores depositan la simiente.

Ya se mencionó que en el área de estudio -y, en buena parte del territorio que ocupó el Matlatzinco- es posible distinguir dos grupos de cultivadores, quienes efectúan la siembra en respectivas etapas (Entrevista No. 7, mayo 2007), utilizando distintas variedades de maíz, como veremos en seguida. En el valle de Ixtlahuaca-Jocotitlán el inicio de la siembra es llamado "marceño" - a lo que se ha hecho referencia con 
anterioridad-, ya que se realiza desde el 20 de marzo, mes en el que se siembra principalmente la semilla "floja" que tarda más en completar su ciclo y corresponde al maíz blanco. En cambio el segundo comienzo de siembra, en el mes de abril o “abrileño", se siembra la semilla denominada "violenta" - por ser de ciclo más rápido-, que pertenece al maíz negro. También se siembra cacahuacintle en abril, "con la esperanza de que llueva a principios de mayo". Es común sembrar maíz asociado con haba.

Ambos inicios de siembra son semejantes a los que tienen lugar en la zona lacustre del antiguo Matlatzinco (ALBORES, 2002 p.255), en concordancia con los cuales encontramos sendos grupos. El de los "marceños", el cual siembra entre el 19 o 21 de marzo hasta fines de este mes, como se indicó, y el de los no-marceños -que comprende a la mayoría de los cultivadores-, que realiza la siembra entre el 6 de abril y el 15 de mayo.

En el valle de Ixtlahuaca-Jocotitlán -de manera similar a la zona lacustre del Matlatzinco- no se considera conveniente prolongar la fase de siembra después de mediados de mayo, señalándose que "para una cosecha segura debe sembrarse del 15 de marzo a fines de abril". Al respecto, los vecinos del área de estudio suelen decir que "el que siembra en mayo es pastura para el caballo" (Entrevista 3, abril, 2007). No obstante, sembrando hasta el 15 de mayo aún puede lograrse la cosecha. Ahora bien, si "no llueve, antes del 15 de mayo", varios cultivadores siembran "avena para los animales" (Entrevistas, 2007).

Con anterioridad, en el área de estudio se sembraba con "pala" de madera, que en la zona lacustre se denomina "coa". Es de una sola pieza; mide aproximadamente dos metros de largo y consta de tres secciones: a) una parte media, delgada y larga, que es por donde se empuña el instrumento, b) un extremo en forma de pala o paleta con la que, antes de abrir el agujero donde se introducirá la simiente, se remueve la capa seca superior del terreno, para dejar al descubierto la tierra húmeda que se sitúa menos superficialmente, y c) el extremo opuesto al anterior que consiste en una punta ${ }^{42}$ endurecida al fuego, con la cual se cava el agujero en el que se deposita la simiente (ALBORES, 2002 p.254). Actualmente ya no se utiliza la pala; fue substituida por la sembradora con máquina de "tubo", que consiste en un arado, movido por animales

${ }^{42}$ Este tipo de coa, la "pala", se observó en el área de estudio, si bien la punta estaba forrada de metal. 
(caballos), con un aditamento cilíndrico o tubo, por donde el peón va echando la semilla (Entrevistas, mayo 2007). De manera semejante, en la zona lacustre se usó la máquina sembradora para maíz y haba. La máquina la conducía un trabajador y era remolcada por una o dos "cémilas" (acémilas). Al moverse, la máquina hacía girar un disco que permitía la salida de dos o tres granos de maíz, contenidos en un bote. Así, el maíz caía en la tierra que había sido abierta previamente por una reja, que formaba parte de la máquina. En seguida, la simiente era tapada con la tierra removida por una paleta, que era otro aditamento de la máquina. Atrás del bote, la sembradora tenía un tubo por donde se dejaban caer manualmente las semillas de haba, procurando que la distancia entre cada grano fuera mayor que la que mediaba entre los granos de maíz (ALBORES, 2002 p.255).

La Santa Cruz de mayo. Cuando las planicies y los cerros muestran la sequedad del ambiente se lleva a cabo la segunda fiesta del año, correspondiente al grupo A. Se trata del "día de la Santa Cruz", el 3 de mayo, que señala el inicio ritual de la época lluviosa. Los santuarios de la región se animan con los festejos de la Santa Cruz; se acostumbra adornar las cruces que se encuentran en dichos santuarios, como el del cerro de Jocotitlán. Acá se celebra una misa, se comparten alimentos y se convive con la gente que asistió a los otros santuarios de la región.

Es común observar en las comunidades del área cruces en diferentes lugares; por ejemplo, siempre hay cruces y altares a pie de carretera, señalando el lugar del fallecimiento de una persona por accidente. También están las cruces que delimitan los barrios de cada comunidad y en la parte alta de las trojes. En su interior, las viviendas generalmente tienen un altar con imágenes religiosas y una cruz. Ésta con frecuencia se coloca arriba o al frente de las obras en construcción, el 3 de mayo, "día del albañil”, ocasión en la que los trabajadores y los dueños de la obra asisten a misa, comen y beben.

Durante la temporada de lluvias, los pequeños depósitos acuáticos empiezan a proliferar en las planicies, como se observa en la foto 1. 


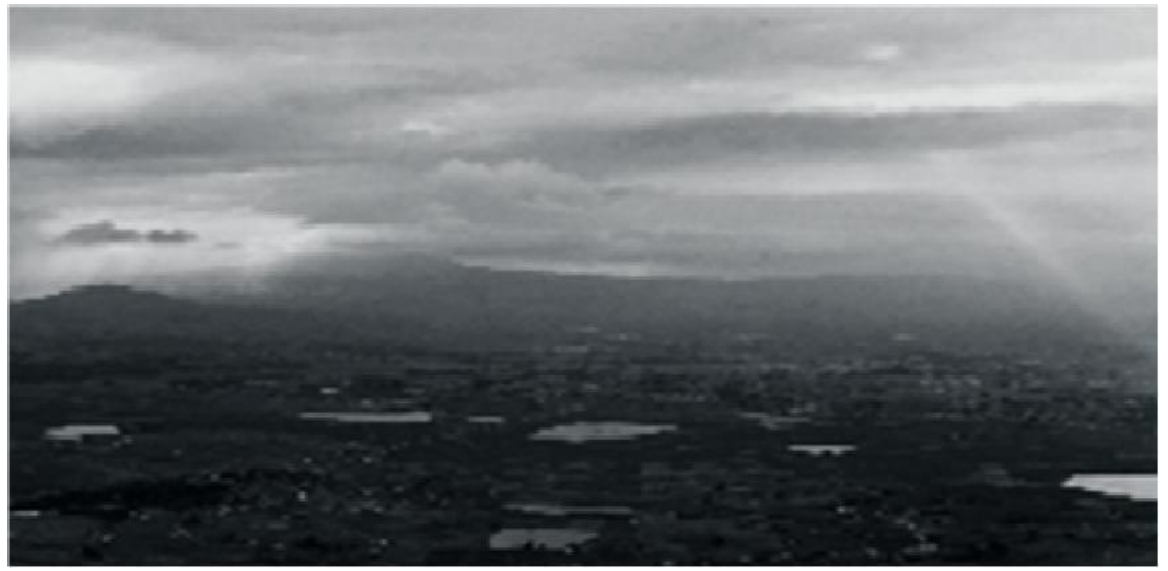

Figura 3: Vista parcial del Valle de Ixtlahuaca-Jocotitlán

Lugar de confluencia de otomíes y mazahuas

(Foto: Guadalupe Barientos, 1999, en BARRIENTOS, 2004:08)

Cuando se atrasan las lluvias y el tiempo está muy seco se lleva a cabo la petición de lluvias, habiéndose identificado, para el valle de Ixtlahuaca-Jocotitlán, tres ceremonias:

a) "Rogaciones" para que llueva. Tienen lugar en la iglesia durante el mes de mayo; se reza el rosario por las tardes y se ruega por las lluvias. En el rosario participan niños y se llevan flores. Al terminar "los cinco misterios y las diez aves marías y, antes de la letanía, se lanzan las flores al cielo diciendo lo siguiente: bajo tu amparo señor nos acogemos para que nos mandes la lluvia”.

b) Procesión para pedir la lluvia, que se realiza a fines de mayo y, en caso necesario, a principios de julio. Se sacan las imágenes de "los santiaguitos" en la procesión que recorre todo el pueblo y se pide la lluvia para el maíz. En él área de estudio se conoce a las imágenes de Santiago Apóstol y San Miguel Arcángel, como los "Santiaguitos”, los cuales están ubicados, respectivamente, en los extremos izquierdo y derecho del altar del templo de Santiago Yeché.

c) "Toque de campanas". Este acto ceremonial consiste en el repique de campanas y tiene un carácter doble puesto que, por una parte, se realiza como súplica para que 
llueva. Y también se acostumbra tocar las campanas de la iglesia cuando se observa que se avecina una tormenta, por lo que se pide que ésta no "arrase con los cultivos".

Barrientos (2004, 2001 p.106-126) menciona que después de la bendición de las semillas se acostumbra efectuar "la petición de lluvias, ya que se acerca el tiempo de la siembra. Así, "el primer domingo de marzo se realiza la peregrinación" hasta el santuario del Señor del Cerrito o “'Señor de la Aguas' -que pertenece a los municipios de Ixtlahuaca y Jocotitlán-, en la que participan pueblos de toda la región”.

En la zona lacustre del antiguo Matlatzinco, el "Día de la Santa Cruz" se celebra en las fechas dobles del 2 al 3 de mayo. El día 2, los quicazcles suben hasta el santuario, en la cúspide del volcán Olotepec -que se sitúa al oriente del Nevado de Toluca- para dar inicio ritual a la época lluviosa del año trópico y pedir, entre otras cuestiones, por el maíz y por el bienestar del pueblo. La actividad ceremonial en el santuario se enmarca en las creencias de origen mesoamericano, con base en las cuales se rinde culto a "todos los montes eminentes" -indica Sahagún (2000, t.I p.72,120,125,135, t.III p.11, 34), sobre todo, en los que "se arman nublados para llover", ya que "imaginaban que eran dioses". Éstos, llamados Tlaloque en náhuatl, estaban presididos por EhécatlQuetzalcóatl y comprendían al propio Tláloc, a Chalchiuhtlícue, así como, entre los "montes" más altos, al Nevado de Toluca. Los Tlaloque mandaban la lluvia y "todas las cosas de mantenimientos que se crían sobre la tierra" a fin de "sustentar la vida" humana. En la fiesta de la Santa Cruz, los saudinos de Techuchulco, además de las compuertas del Olotepec, abren las denominadas "llaves" del pueblo para que llegue el agua pluvial.

C) Abonamiento, escarda y deshierbe. Si llueve a mediados de mayo se abona por segunda vez la tierra con urea y se realiza la primera "escarda"; es decir, se acerca la tierra de abajo del surco hacia el tallo, cubriendo su parte inferior para afianzarlo y para que la planta pueda desarrollarse adecuadamente. El deshierbe se efectúa de fines de mayo a principios de junio, generalmente de forma manual o bien fumigando con líquido "mata hierba" para eliminar las especies vegetales dañinas como la “calabacilla", el "polvillo" y el "chayotillo". Se trata de plantas trepadoras que al subir a la mata de maíz por lo general la secan, pudiendo incluso derribarla. En el caso de la 
"avena silvestre", se permite su crecimiento para cortarla conforme se requiere pastura para los animales caseros.

Hacia fines de junio despuntan los jilotes de la planta de maíz - lo cual es una señal de que la mazorca está creciendo adecuadamente- y, para julio, el jiloteo está en su plenitud.

En el área de estudio, desde la tercera fase del ciclo agrícola se lleva a cabo cierto control del agua de lluvia para el riego de los predios de la planicie. El líquido pluvial se capta en jagüeyes para después transportarlo a través de zanjas que los mismos campesinos construyen en dirección a sus cultivos. Se abren salidas en lugares convenientes, procurando que el terreno reciba agua suficiente para el crecimiento de la planta. Como es posible observar, estamos ante un segundo recurso técnico con el que se procura tener agua para poder concluir felizmente el ciclo agrícola. El primer recurso favorece la germinación de la semilla, mediante la captación de la humedad a partir del agua del entorno y de las lloviznas eventuales que, congelándose en la noche, se derrite a lo largo del día. Esto es, a diferencia del agua, con la que se humedecían los terrenos de San Mateo Atenco antes de las lluvias, que provenía en buena medida de la nieve derretida del Nevado de Toluca, como vimos. De manera que esta forma de la variante local del sistema de humedad y temporal incorpora el riego con agua de lluvia.

D) Cosecha. Fase que comprende dos etapas fundamentales: el corte del fruto tierno y el saje del maíz maduro.

Corte del fruto tierno. La primera etapa de cosecha corresponde al corte de los "elotes tiernos", que se emprende en el mes de agosto, después de la celebración religiosa, a la que nos referimos en seguida.

La fiesta del maíz. El 15 de agosto, las familias campesinas y del medio rural llevan a cabo la tercera celebración religiosa, perteneciente al grupo A. Es la fiesta del fruto tierno del maíz, que recibe varios nombres, si bien en alusión a un mismo acontecimiento: el corte de los primeros elotes tiernos. Así, algunos de dichos nombres son: "fiesta del maíz", "estreno de la milpa", "florear la milpa"-o, en plural: "florear las milpas"- y "estreno del elote". Se trata de la segunda fiesta del grupo A, cuyo nombre se refiere, de manera directa, a una etapa del ciclo agrícola, si bien, en algunos pueblos 
se festejan distintas advocaciones de la virgen María, como veremos con mayor detenimiento en seguida.

La denominación de la fiesta del 15 de agosto: "florear las milpas" se utiliza debido a que en la orilla de éstas se colocan pequeños manojos de flores silvestres (cantúes de color morado, flor de fuego, flor casera, malvón, bola de fuego) o flores cultivadas (gladiolo, rosa o dalia). Los manojos se atan en la parte superior de las cañas del maíz. Para los campesinos, la fructificación tierna del maíz se concibe como una "bendición de las milpas", por lo que festejan alrededor de los sembradíos, convidándose comida y bebida (Entrevistas y observación, agosto 2007). En el área de estudio esta celebración también se llama "estreno de la milpa" porque se cortan los primeros elotes tiernos para comerlos en familia (Entrevistas y observación, agosto 2007).

En la comunidad de Tiacaque se festeja "el 15 de agosto a la Virgen del Rosario". Se celebra una misa para agradecer que la planta del maíz vaya creciendo bien y por el logro de buena cosecha al final del año. El 15 de agosto los campesinos acostumbran "florear la milpa" durante "la fiesta del maíz", cuando tiene lugar el "estreno" del elote. Se cortan algunos "elotes tiernos" y se cuecen para consumirlos junto con familiares y amigos" (Entrevistas, abril; 2007).

"En el barrio de Boyecha, de Santiago Yeché, también se acostumbra florear la milpa el día 15 de agosto y se festeja a la virgen de Tránsito" (Entrevista o. 4, mayo 2007). Los vecinos creen que el 15 de agosto baja la virgen de Guadalupe y le gusta ver las milpas adornadas, ya que es el día del "estreno de la milpa". Al respecto, don Modesto señala que se compra una "mantada" - es decir, una buena cantidad de florpara "adornar la milpa". Esta ceremonia se realiza en familia, con la participación de todos sus integrantes, principalmente las mujeres. Antes se colocaba un arco de flores en cada una de las esquinas de la milpa.

En el ejido de San Francisco Chejé, uno de sus barrios se llama "15 de agosto", donde también se festeja el "estreno de la milpa" con una misa en el templo, situado en el centro del barrio. La gente se reúne para la fiesta. Cada familia lleva alimentos preparados con maíz: tortillas, tamales, elotes cocidos, esquites, para convidarse, después de la misa, comida y bebida (pulque, refrescos y agua). 
Así, el 15 de agosto, que el calendario de fiestas católicas marca como la fecha conmemorativa de la "Asunción de la santísima virgen María" (GALVÁN, 2008 p.140), en el área de estudio no se celebra a la virgen de la Asunción. En efecto, como hemos visto, se celebra a la virgen de Tránsito, a la del Rosario y a la de Guadalupe, en tanto que el propio festejo lleva los nombres de "florear la milpa", "fiesta del maíz", "estreno de la milpa" y "estreno del elote".

Lo anterior expresa que la población otomiana del valle de Ixtlahuaca-Jocotitlán festeja porque el maíz ya prodigó sus frutos tiernos, a lo que le llaman la "bendición de las milpas". Es, entonces el "estreno de la milpa" o "estreno del elote", cuando la familia debe "florear las milpas" porque, de acuerdo con la forma de conceptuar el mundo de origen mesoamericano, la planta que prodiga el maíz tierno es el árbol sagrado por excelencia, el árbol cósmico florido (ALBORES, 1997 p.224-439). Así, nos parece que el carácter de la fiesta, que se observa en esta área, alude de manera directa a su referente mesoamericano, lo cual permite establecer una correspondencia de esta celebración religiosa con el lapso anual en el que tiene lugar la fase agrícola respectiva. Ello fundamenta la posibilidad de su articulación con la cuenta calendárica mesoamericana de 365 días, en una variante fija relativa al año trópico de 365.2422 días, a lo que nos referiremos al tratar el carácter orgánico del grupo A y del conjunto de ocho fiestas.

En la zona lacustre, los festejos de la Asunción de la Virgen -que también se conoce como la Asunción de Nuestra Señora, Santa María la Asunción o sólo "La Asunción"- tiene lugar en las fechas dobles del 14 al 15 de agosto, cuando se celebra "la fiesta de los elotes" o "fiesta de la caña" del maíz. El día 14, los graniceros regresan al Olotepec para dar comienzo ritual a la cosecha de los frutos tiernos del maíz: los elotes y las cañas dulces y para agradecer a las entidades sagradas por las favorables "lluvias eloteras". Es la celebración más importante del grupo A que celebran los graniceros, en la que entran a la hermandad los nuevos elegidos, es decir, los que han sido golpeados por el rayo desde la última fiesta de la Asunción. También se trata de la fiesta principal de la población campesina y rural que sube al Olotepec (ALBORES, 1997p.421-422). Como puede observarse, si bien en la zona lacustre dos de los nombres de la fiesta se refieren a la etapa agrícola correspondiente - en la que se cosecha el maíz 
tierno en forma de elotes y la caña dulce-, el apelativo común es el de la Asunción de la Virgen.

Siega del maíz maduro. La segunda etapa de cosecha corresponde al corte del fruto totalmente maduro que en el área de Ixtlahuaca-Jocotitlán se acostumbra llevar a cabo en los meses de noviembre a diciembre. A mediados de octubre caen las últimas lluvias - con las que habrá de concluir la temporada húmeda para dar comienzo a la época seca, siendo entonces cuando se emprenden los preparativos para el saje del fruto maduro.

La divisoria ritual y conceptual entre la época lluviosa y la de sequía es la fiesta de los "santos difuntos" -el $1^{\circ}$ y 2 de noviembre-, la cual marca el inicio de la segunda etapa de la cosecha. Pasando esta festividad las familias campesinas efectúan la siega del fruto macizo. Luego almacenan en "cincolotes"43 las mazorcas de maíz amarillo o "criollo" y negro, por separado. Es costumbre escoger un padrino, quien bendice y coloca una cruz en la cima del cincolote. El padrino será aquella persona que durante la cosecha encuentre una caña con dos mazorcas en forma de cruz.

De manera similar, en la zona lacustre la cosecha del maíz maduro comienza después de la fiesta denominada "La llegada de los Muertos" o sólo "Muertos", que se realiza en las fechas pareadas del $1^{\circ}$ al 2 de noviembre, como en el área de IxtlahuacaJocotitlán. Al respecto conviene mencionar que entre los lapsos festivos de la fiesta de Muertos, en la región del antiguo Matlatzinco, se cuentan los que van del 28, 29 o 30 de octubre al 2 o 4 de noviembre, pudiendo ampliarse, en el territorio que abarcó Mesoamérica, desde antes del 28 y hasta todo el mes de noviembre. En esta conmemoración, los quicazcles van por última vez al volcán sagrado del Olotepec, el día 2 de noviembre, para marcar el fin ritual de la época de lluvias y, como se anotó, el comienzo de la cosecha del fruto macizo del maíz.

E) Corte y almacenamiento del rastrojo. Es la fase relativa al corte manual del rastrojo o zacate seco que proviene del ciclo recién concluido. Después de su corte, el zacate se recoge y se almacena en pacas, que se colocan en la parte trasera de la casa-habitación.

\footnotetext{
${ }^{43}$ Estructura rectangular hecha de maderos entrecruzados a fin de permitir la ventilación de las mazorcas, las cuales se desgranan poco a poco durante todo el año para la alimentación diaria -a base de tortillas, sobre todo- del grupo doméstico.
} 
El rastrojo se emplea principalmente para alimentar a los animales caseros, como caballos, vacas y borregos, que por lo común posee cada familia campesina.

La fiesta del 6 de enero en el santuario de la Capilla (del municipio de Jiquipilco) articula a la última fase del ciclo agrícola y la del nuevo ciclo con la fiesta de la Virgen de la Candelaria, el 2 de febrero.

\section{Fiesta patronal en Jocotitlán}

La fiesta del santo patrón -o tutelar- constituye uno de los ejes articuladores de la actividad religiosa en los municipios mexiquenses, en sus poblados y barrios donde aún persiste la tradición campesina y rural (ALBORES, 2004, p.5). Son conmemoraciones que forman parte del calendario religioso y se relacionan en primera instancia con los ciclos agrícola y meteorológico, que atañen al cultivo del maíz de temporal de origen mesoamericano. A continuación nos referiremos a la fiesta tutelar de Santiago Yeché, perteneciente al municipio de Jocotitlán.

La celebración patronal ${ }^{44}$ de Santiago Yeché se celebra cada 25 de julio y es conocida como "la fiesta grande". Su organización constituye un compromiso anual de los grupos de cargueros, a los que hicimos referencia con anterioridad, que localmente son llamados "comités" y "mesas directivas". La elección de los cargueros recae en personas con prestigio dentro de sus comunidades, quienes se organizan para recabar la cooperación de los vecinos. Ésta se utiliza en la contratación de la música y en la compra de cohetes, flores - para adornar la fachada del templo- y comida para los obispos, sacerdotes e invitados, entre otros rubros.

El ejido de Santiago Yeché se divide en nueve barrios, en los que se efectúan respectivas peregrinaciones, entre el 17 y el 25 de julio. El recorrido se lleva a cabo desde el centro de cada barrio hasta el templo del Señor Santiago, ubicado en el centro de Santiago Yeché. Los vecinos llevan ofrendas que consisten en cañas frescas de maíz jiloteado, flores, sahumerio y veladoras.

La novena y última peregrinación tiene lugar el 25 de julio y le corresponde al barrio de "Engaseme", que se sitúa en el centro de Santiago Yeché. La peregrinación se realiza al término de la llamada "misa grande" con la gente que asistió a ésta. Se

${ }^{44}$ Asisten diversas comunidades de la región del Valle de Ixtlahuaca, Estado de México. 
recorren las principales calles del pueblo y cada participante lleva una flor de gladiola roja (gladiolus $s p^{45}$ ) en la mano. La imagen de bulto del Señor Santiago -que es cargada en hombros por cuatro o seis voluntarios varones-y el sacerdote van al frente de los peregrinos y, al final, una banda de música. Durante el novenario de peregrinaciones, se observa la intensa red de relaciones que se genera entre los vecinos de los barrios (Observación, julio, 2007).

El Señor Santiago es, como quedó anotado, uno de los dos santos que se sacan en procesión para pedir la lluvia, cuando ésta escasea, al finalizar el mes de mayo y al comienzo de julio, lo cual denota el gran poder que se le adjudica al santo patrono, de manera inicial sobre el tiempo meteorológico en su vínculo con el cultivo del maíz. Así, el párroco de Santiago Yeché indica que la gente acostumbra "pedir, durante la celebración de las misas" dominicales y en la "fiesta del pueblo, por sus cultivos" al santo patrono y al "cerro de Jocotitlán". También "es muy común" que los vecinos dejen "mazorcas junto al santísimo sacramento o junto a la imagen del Señor Santiago" (Entrevista, julio 2007). Se trata de la ofrenda en reciprocidad por el vigor y el sustento que los vecinos reciben del santo patrono de Santiago Yeché y de Dios. Subyace, entonces, una noción de intercambio que se expresa en la relación con las divinidades. Es decir, los peregrinos alimentan o nutren a la divinidad -mediante las mazorcas de maíz- y esperan recibir, en contrapartida, una acción similar: el logro de sus cultivos.

Ahora bien, el cerro de Jocotitlán es, según las creencias de origen mesoamericano, una de las deidades de las que, como vimos, proviene no sólo la lluvia sino también el grano divino del maíz, es decir, los mantenimientos. Puesto que, históricamente, los indígenas del área de estudio otorgan a los cerros un lugar central en muchos aspectos de su vida, en su cumbre han ubicado espacios de culto, como hemos visto en lo relativo al volcán Olotepec. En este contexto, se cree que los cerros están emparentados entre sí, lo mismo que las entidades que ahí son consagradas.

Así, el cerro de Jocotitlán es cuidado y venerado por sus habitantes quienes le piden permiso cada vez que van a extraer plantas o animales comestibles como hongos, madera y conejos, entre otros. También se acostumbra que quien atrapa un coyote lo muestre, casa por casa, para que se le reconozca como "protector" de los beneficios que

\footnotetext{
${ }^{45}$ Flor cultivada en la región por algunas unidades domésticas campesinas, como cultivo comercial alterno al cultivo de maíz. Para mayor información sobre los cultivos comerciales en la región consultar (REYES, 2006).
} 
ofrece el cerro de Jocotitlán, ya que el coyote es considerado como un animal dañino tanto para algunas especies del cerro como para la sociedad.

De manera que, por la capacidad creadora de los santuarios y de las divinidades que habitan en ellos, los peregrinos piden, en determinadas fechas, por los productos de la tierra y por la lluvia. Lo anterior se expresa en numerosos relatos en los que se concibe a los cerros como sitios de riqueza. Para los campesinos los cerros sagrados son "dadores" de las lluvias, de la energía y del sustento, razón por la que se les relaciona con la fertilidad agrícola y la fecundidad humana, con la salud y el bienestar de la población (Entrevista, julio, 2007). Es decir, así como los santuarios y sus divinidades dispensan "fuerza" al maíz y a los demás frutos, también la otorgan a los hombres y mujeres que acuden a ellos (BARRIENTOS, 2004, 2001 p.129-130).

En lo que respecta a las peregrinaciones, éstas constituyen espacios en los que se establecen relaciones que aportan grandes beneficios colectivos, ya que implican obligaciones de ayuda recíproca. Esto es, en el ámbito ritual y en otras actividades económicas y sociales que se realizan a lo largo del año, como la siembra y la cosecha, pertenecientes al ciclo agrícola, y por ejemplo, el bautizo, relativo al ciclo humano de vida. Al respecto, en la fiesta grande confluyen, ritualmente, los ciclos agrícola y meteorológico (a los que ya nos referimos) con el ciclo humano de vida. En efecto, durante la misa del día 25 de julio hacen su primera comunión aproximadamente entre 400 y 500 niños de las comunidades del área de estudio; cada uno es apadrinado por algún pariente o amigo reforzando así las relaciones del sistema de compadrazgo locales (entrevista mayo 2007).

En este marco, la relación entre los participantes en la vida ceremonial está definida por la acción de compartir. Así, después de la misa y la última peregrinación del día 25 de julio, se llevan a cabo comidas colectivas en la plaza central de Santiago Yeché; alrededor del templo católico, las familias se agrupan y se convidan los alimentos. Para los campesinos de esta región, el compartir en cualquier situación ritual se define como la adquisición simbólica de un compromiso con el grupo social al que pertenecen. Las grandes transferencias de recursos para las festividades y peregrinaciones son sólo ejemplos, de cómo se activan tales redes de obligaciones recíprocas. 
Estas celebraciones religiosas, en las que destacan las procesiones y ofrendas en torno a un "santo patrono", dan un sentido de identidad y pertenencia a los barrios y fortalecen los vínculos solidarios en cada comunidad. Es decir las peregrinaciones, ofrendas y rogaciones muestran la estrecha relación entre las ceremonias religiosas y la agricultura, en particular, el cultivo del maíz.

\section{Las fiestas en cruz del valle de Ixtlahuaca-Jocotitlán}

El tiempo cósmico. Los quicazcles del Olotepec celebran anualmente de manera obligatoria, como se dejó anotado, las fiestas que integran el grupo A: la Candelaria, la Santa Cruz, la Asunción de la Virgen y la Llegada de los Muertos o Muertos, las cuales tienen lugar en respectivas fechas dobles del $1^{\circ}-2$ de febrero, 2-3 de mayo, 14-15 de agosto y $1^{\circ}-2$ de noviembre. La actividad ritual de los quicazcles en las cuatro fiestas les confiere una cualidad orgánica o estructural, por lo que integran una estructura de cuatro fiestas. El carácter orgánico de éstas se expresa, entre otras cuestiones, por la dimensión de su ciclo, del cual constituyen respectivos hitos del camino o curso que, por haber sido señalados, deben realizar anualmente los quicazcles. Se trata de un curso o ciclo fijo que comprende tres cuentas de 260, 263 y 265 días, puesto que abarca desde la fiesta de la Candelaria, el 12 de febrero gregoriano -equivalente a la fecha pareada del 2 de febrero juliano- hasta tres fechas del lapso festivo de la conmemoración de Muertos: 30 de octubre, 2 y 4 de noviembre ${ }^{46}$.

\section{El grupo A de fiestas}

Las cuatro fiestas del grupo A, como se mencionó, y sus tres cuentas expresan la forma mesoamericana de conceptuar el tiempo-espacio, relativo al proceso universal que incluye todos los ciclos. Entre éstos destacan, por su trascendencia en la cultura mesoamericana, seis tipos: agrícola, meteorológico, humano, mítico, astronómico y calendárico, a los que se hará referencia. La alusión ritual y conceptual a estos ciclos puede observarse en numerosos aspectos de las cuatro fiestas, a algunos de los cuales, que corresponden a la fiesta de la Candelaria, se hará una mención breve, por haber sido 
tratados de manera más amplia en otro lugar (ALBORES, 2006b). En efecto, en los pueblos de la zona lacustre se bendicen, durante dicha fiesta, distintos elementos que se usarán o podrían usarse a lo largo del año, en algunos de los ciclos cósmicos.

1) El ciclo menor ${ }^{47}$ del maíz abarca 263 días. Esto es desde que, como grano duro o simiente, se bendice y en algunos pueblos se siembra (en la fiesta de la Candelaria, como se dejó anotado) hasta que fructifica y, también como grano macizo, está listo para su cosecha. Puede decirse que dicho lapso se extiende a partir de que el grano maduro se introduce o está en condiciones para colocarse y desaparecer en la tierra hasta que reaparece transformado en planta, crece y produce múltiples granos, que vuelven a endurecerse.

2) El ciclo meteorológico menor, que corresponde a la época lluviosa, se ubica -de la fiesta de la Santa Cruz a la de Muertos- dentro del ciclo con sus tres cuentas de 260, 263 y 265 días. Entre los elementos que se bendicen el 2 de febrero se encuentran velas y vegetales, para favorecer un buen ciclo meteorológico, como también se ha mencionado con anterioridad.

3) El ciclo humano menor que, en lo relativo al tiempo que tarda la mujer en gestar, cubre alrededor de 260, 263 o 265 días, es decir, nueve ciclos sinódicos de la Luna $^{48}$. Y, en lo que se refiere a una de las formas mesoamericanas, la menor, de contar el ciclo humano de vida, a partir del nacimiento, con base en cuentas sucesivas de 260 días. Algunos de los elementos que se bendicen el día 2 de febrero son pan, monedas, pequeños petates, elementos vegetales, y otros más, para emplearse en los principales momentos del ciclo de vida humano, como son el parto/nacimiento, el matrimonio y la muerte.

4) El ciclo mítico menor, en referencia a la ubicación espacio-temporal de los cuatro árboles cósmicos, señalada por las fiestas del grupo A dentro del ciclo de 260, 263 y 265 días. Uno de los elementos que se llevan a sacralizar el 2 de febrero son cerillos "para cuando ocurra el fin del mundo" o ciclo mítico. Ciclo que se inició con la creación del último Sol o era -que aún nos rige-, cuando como se indica en la Historia de los mexicanos por sus pinturas (1996:32)- los

\footnotetext{
${ }^{46}$ Para ver con mayor amplitud lo relativo a las tres cuentas -de 260, 263 y 265 días- y a las fechas del 30 de octubre y 2 y 4 de noviembre, consultar (ALBORES, 2006b p.94-96).

${ }^{47}$ El ciclo menor ha sido llamado "ciclo parcial" en (ALBORES, 2006b p.101).

${ }^{48}$ El periodo sinódico lunar abarca el tiempo de rotación del astro en torno a la tierra, el cual corresponde a 29.53059 días (AVENI, 1991p.193). Por ello, nueve periodos de la Luna comprenden 265.7731 días.
} 
cuatro dioses, particularmente Quetzalcóatl y Tezcatlipoca -hijos de la pareja primigenia- "alzaron el cielo" (que se había colapsado sobre la tierra) "con las estrellas como agora está". El 2 de febrero se bendicen mazorcas de maíz de distintas variedades, cuyos colores aluden a los cuatro árboles cósmicos que fueron puestos por los cuatro hermanos. En efecto, estos dioses, luego de que el cielo había caído sobre la tierra, acordaron -según se lee en la Historia de los mexicanos por sus pinturas (1996:23-36) - cavar "por el centro de la tierra cuatro caminos, para entrar por ellos y alzar el cielo".

5) El ciclo astronómico menor, en lo correspondiente a la visibilidad vespertina de Venus, que cubre 263 días en promedio. Mediante la participación en las fiestas del grupo A, los quicazcles caminan, ritual y conceptualmente cada año como se indicó, un ciclo astronómico: el de Venus vespertino, el cual constituye la manifestación astral de Ehécatl-Quetzalcóatl. Al respecto, cabe mencionar que los graniceros de la región que ocupó el Matlatzinco eran nombrados "barrenderos" a inicios del siglo XIX. Ello se debe a que al morir por el golpe del rayo, que Tláloc les mandaba, los graniceros pasaban a formar parte de Quetzalcóatl, el "dios de los vientos” que, como lo indica Sahagún (2000, t.II:73), "barría los caminos a los dioses de la lluvia para que viniesen a llover". De ahí, nos es dable interpretar ${ }^{49}$ que quienes sobreviven al llamado que, por el rayo, hace Tlaloc -o Dios en nuestros tiempos- también pasan a pertenecer a Quetzalcóatl, es decir, no sólo a ser sus servidores sino también parte suya. Ahora bien, el ciclo astronómico, que de manera conceptual $^{\mathbf{5 0}}$ efectúan anualmente los quicazcles, se extiende del 12 de febrero al 2 de noviembre, cubriendo 263 días.

6) El ciclo calendárico menor. El recorrido anual que, como parte de su carga cósmica, realizan los quicazcles, incluye otra fecha de la fiesta de Muertos: el 30 de octubre, como hemos visto. De manera que entre el 12 de febrero y el 30 de octubre se establece un lapso de 260 días, que es lo que abarca uno de los ciclos

\footnotetext{
${ }^{49}$ El fundamento de tal interpretación se encuentra en (ALBORES, 2006b p.99).

50 Sobre el nombre de "barrenderos", que se les asignaba a los graniceros del antiguo Matlatzinco, a principios del siglo XIX, y acerca del carácter conceptual del recorrido que efectúan los quicazcles anualmente consultar (ALBORES, 2006b p.96-100), correspondiente a los incisos: "la Articulación con Venus vespertino" y "Los barrenderos cósmicos".
} 
calendáricos más importantes de origen mesoamericano, llamado tonalpohualli en náhuatl y tzolkin para los mayas.

A partir de sus características, podemos observar que el grupo A $-\mathrm{y}$ sus tres cuentas- alude al aspecto nocturno, femenino del universo, por sus implicaciones a Venus vespertino, a la Luna y a la Tierra.

\section{El grupo B de fiestas}

El grupo A se articula de manera orgánica con cuatro fiestas más -o grupo B-, como ya se ha indicado. Las fiestas del grupo B se mencionarán en seguida, en su vínculo inicial con el cultivo del maíz de temporal.

1) San José, que se festeja el 19 de marzo para indicar ritualmente y propiciar la siembra "marceña" del maíz, eventos que están señalados por el equinoccio de primavera.

2) San Juan, cuya celebración -que tiene lugar el 24 de junio en alusión al crecimiento de la planta de maíz- está indicada por el solsticio de verano.

3) San Mateo. Se conmemora el 21 de septiembre para marcar la etapa de endurecimiento del maíz y tiene como referente al equinoccio de otoño.

4) El nacimiento del niño Dios. Esta celebración se efectúa el 24 de diciembre en referencia a uno de los cierres de la cosecha del maíz maduro, así como para agradecer su consecución y está marcada por el solsticio de invierno.

El grupo B cubre un ciclo - de 365.24222 días- que corresponde al año trópico y también alude a los seis tipos de ciclos, como se verá en seguida.

1) Ciclo mayor ${ }^{51}$ del maíz. Tiene lugar durante el año trópico e incluye, además de la cosecha del fruto macizo (que comienza pasando la fiesta de Muertos), el levantamiento de los residuos secos: hojas, tallo y raíz de la planta madre.

\footnotetext{
${ }^{51}$ El ciclo mayor se ha nombrado "ciclo total” en (ALBORES, 2006b).
} 
2) Ciclo meteorológico mayor que abarca no sólo la temporada lluviosa sino también la de sequía, la cual se extiende de la fiesta de Muertos a la de la Santa Cruz.

3) Ciclo humano, en lo referente a la cuenta mayor, de 365 días, con base en la cual se realizaba -y se realiza- otro de los registros de dicho ciclo vital.

4) Ciclo mítico, en lo que atañe a la ubicación mayor de los árboles cósmicos, indicada por las fiestas del grupo B.

5) Ciclo astronómico, en relación con el ciclo solar, de 365.2422 días.

6) Ciclo calendárico mesoamericano, de 360+5 días, denominado xiuhpohualli por los mexica y haab por los mayas.

Por lo expuesto, es posible plantear que el grupo B, así como sus cuentas, hacen alusión al aspecto diurno, masculino del universo, mediante su implicación al astro solar.

\section{El conjunto de ocho fiestas}

Los grupos A y B se imbrican, entre otras cuestiones, a través de sus respectivas cuentas -de 260 y 365 días-, integrando el conjunto de ocho fiestas, como se señaló. Dichas cuentas aluden al nexo dialéctico de los principios femenino y masculino y expresan, de manera estructural, el movimiento, es decir, el proceso o los procesos universales del tiempo cósmico. Éste ha sido conceptuado como: vida-muerteresurrección en la cultura mesoamericana. Se trata de una conceptuación del mundo que se funda en las cuentas calendáricas de 260 y 365 días, cuya articulación caracterizan, culturalmente, a Mesoamérica.

\section{Corolario}

El caso del valle de Ixtlahuaca-Jocotitlán es de particular interés debido a que nos ha permitido conocer una variante agrícola de humedad y temporal con dos formas. Ésta constituyó uno de los más importantes sistemas de la región que ocupó el Matlatzinco y de Mesoamérica, mediante los cuales la planta divina del maíz se ha cultivado desde tiempos remotos. Además, la fiesta del 15 de agosto nos ha mostrado su 
especificidad agrícola, con base en la cual es posible fundamentar la cualidad estructural del grupo A de fiestas, a partir de un entorno natural distinto al de la zona lacustre del alto Lerma mexiquense, donde dicho grupo se encontró por vez primera. Lo que atañe al ritual agrícola posibilita el avance en la comprensión de las formas de conocimiento de origen mesoamericano, tal como ha sido ilustrado en la exposición del caso de Ixtlahuaca-Jocotitlán.

\section{Referências}

ALBORES A., Beatriz, "El desplazamiento de las lenguas indígenas en la Antigua Zona Lacustre del Alto Lerma", Cuicuilco, Año IV, número 16, México, Revista de la Escuela Nacional de Antropología e Historia, 1985, pp. 23-35.

Tules y Sirenas. El impacto ecológico y cultural de la industrialización en el alto Lerma, México, El Colegio Mexiquense, A.C., Gobierno del Estado de México, Secretaría de Ecología, 1995.

"Los quicazcles y el árbol cósmico del Olotepec, Estado de México", en Albores, Beatriz y Johanna Broda (coords.), Graniceros. Cosmovisión y meteorología indígenas de Mesoamérica, México, El Colegio Mexiquense, A.C., UNAM, Instituto de Investigaciones Históricas, 1997, pp. 379-446.

"Los Otomianos del alto Lerma mexiquense. Un enfoque etnológico", Estudios de cultura Otopame 1, México, UNAM, Instituto de Investigaciones Antropológicas. 1998, pp. 187-214.

"Origen pre-mexica de las chinampas de la zona lacustre del alto Lerma mexiquense", Documentos de Investigación 22, Zinacantepec, edo. de México, El Colegio Mexiquense, A.C., 1998 b.

"Apuntes sobre la agricultura maicera de humedad y temporal en San Mateo Atenco, Estado de México" en Revista Ciencia Ergo Sum, noviembre, vol. 9, número 3, Toluca, Universidad Autónoma del Estado de México, 2002.

"Las fiestas religiosas mexiquenses. Un esquema inicial", Documento de investigación 89, Zinacantepec, estado de México, El Colegio Mexiquense, A.C., 2004.

"Una travesía conceptual: Del Matlatzinco al valle de Toluca", en Anales de Antropología Volúmen 40-I, México, Instituto de Investigaciones Antropológicas de la UNAM, 2006a.

"Los graniceros y el tiempo cósmico en la región que ocupó el Matlatzinco", Estudios de Cultura Otopame 5, México, UNAM, Instituto de Investigaciones Antropológicas, 2006b, pp. 71-117. 
AVENI, Anthony Observadores del cielo en el México antiguo, México, Fondo de Cultura Económica, 1991.

BARRIENTOS, Guadalupe, El cerrito Tepexpan: sustentador de vida ritual y reproducción cultural de mazahuas y otomíes en el altiplano de Ixtlahuaca, Tesis de Maestría en Historia y Etnohistoria, Escuela Nacional de Antropología e Historia, México, INAH/SEP,2001.

Otomíes del Estado de México, colección Pueblos indígenas del México Contemporáneo. México, CDI (Comisión Nacional para el Desarrollo de los Pueblos Indígenas): PNUD (Programa de las Naciones Unidas para el Desarrollo),2004.

CARRASCO, Pedro, Los otomíes. Cultura e historia prehispánica de los pueblos mesoamericanos de habla otomiana, México, UNAM, Instituto de Historia e Instituto Nacional de Antropología e Historia, primera Serie, 15, 1950.

CHEDID, Abraham, "programa de restauración de la Cuenca Alta del río Lerma", ponencia presentada el $1^{\circ}$ de junio, en la ciudad de Toluca, durante el Primer congreso estatal de ecología, organizado por el Grupo Ecolgista de Toluca, A.C., 1990.

FABILA, Alfonso, Ensayo socioeconómico del Estado de México, México., 2 vols., 1951.

GALVÁN, $182^{\circ}$ Calendario del más antiguo Galván para el año bisiesto de 2008, México, Librería y Ediciones Murguía, S.A., 2008.

GIMÉNEZ, Carlos, El régimen comunal agrario: estudio comparativo de los bienes comunales en España y México, Tesis doctoral, Madrid, Universidad Complutense, Facultad de Geografía e Historia, Sección de Historia de América, subsección de Antropología y Etnología de América,1985.

GONZÁLEZ, Alba, “Ambiente y Cultura en la agricultura tradicional de México: Casos y Perspectivas", en Revista Ciencia Ergo Sum, julio-octubre, año/vol.11, número 002, Toluca, Universidad Autónoma del Estado de México, 2004.

GUTIÉRREZ, Sylvia (1979), Arqueología del Valle de Ixtlahuaca, Estado de México, México, Biblioteca Enciclopédica del Estado de México, 1979.

HISTORIA de los Mexicanos por sus pinturas, en Garibay Ángel Ma., ed., Teogonía e historia de los mexicanos. Tres opúsculos del siglo XVI (1996), México, Editorial Porrúa "Sepan cuantos.", No. 37, 1996, pp.21-90.

MARIACA, Ramón, ¿Qué es la agricultura? bajo una perspectiva Xolocotziana, México, Universidad Autónoma de Chapingo, Universidad Autónoma del Estado de México, 1997.

PALERM, Ángel, "Sistemas agrícolas en Mesoamérica Contemporánea" en Cuadernos de Antropología: guía y lectura para una primera práctica de campo, Jacinta Palerm, 
M.O. Olvera, P. Torres (compiladoras) 1992, México, Universidad Autónoma de Querétaro, 1971.

POPOL, Vuh. Las antiguas historias del Quiché, Adrián Recinos, trad., introducción y notas, México, Fondo de Cultura Económica, Colección Popular, 1961.

RAMÍREZ, Alberto y AGALLOO Celaya Alejandro Enciclopedia de los Municipios de México, Estado de México Jocotitlán, México, Instituto Nacional para el Federalismo y el Desarrollo Municipal/Gobierno del Estado de México, 2005. Disponible
local.gob.mx/work/templates/enciclo/mexico/r $<$ http://www.elocal.gob.mx/work/templates/enciclo/mexico/mpios/15048a.htm> fecha de consulta:13/07/2007.

REYES, Laura, Estudio Antropológico de una región agrícola al norte del estado de México, Cuadernos de Investigación. Cuarta época Vol. 46, México, Universidad Autónoma del Estado de México, 2006.

ROJAS, Teresa, Historia De la agricultura. Época prehispánica-siglo XVI, México, Instituto Nacional de Antropología e Historia, (Colección Biblioteca del INAH), 1985. (coord.), Agricultura indígena: pasado y presente, México, CIESAS, 1991.

SAHAGÚN, Bernardino de, Historia general de las cosas de Nueva España, México, Porrúa 4 tomos, 1956.

Historia general de las cosas de Nueva España (Versión íntegra del texto castellano del manuscrito conocido como Códice Florentino. Estudio introductoria, paleografía, glosario y notas de Alfredo López Austin y Josefina García Quintana), Cien de México, CONACULTA, 3 tomos. 2000.

SÁNCHEZ, Salvador, El Estado de México. Su historia, su ambiente, sus recursos, t.I, México, Editorial Agrícola Mexicana, 1951.

SOUSTELLE, Jacques, La familia otomí-pame del México central, México, Centro de Estudios mexicanos y centroamericanos, Fondo de Cultura Económica (Sección de obras de Historia), 1993.

Recebido para publicação em março de 2010

Aprovado para publicação em abril de 2010 